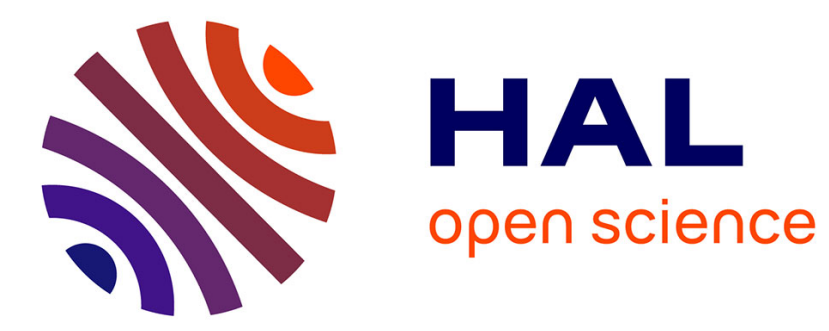

\title{
About thermo-oxidative ageing at moderate temperature of conventionally vulcanized natural rubber
}

\author{
F. Grasland, L. Chazeau, J.-M. Chenal, R. Schach
}

\section{To cite this version:}

F. Grasland, L. Chazeau, J.-M. Chenal, R. Schach. About thermo-oxidative ageing at moderate temperature of conventionally vulcanized natural rubber. Polymer Degradation and Stability, 2019, 161, pp.74-84. 10.1016/j.polymdegradstab.2018.12.029 . hal-02405462

\section{HAL Id: hal-02405462 \\ https://hal.science/hal-02405462}

Submitted on 21 Oct 2021

HAL is a multi-disciplinary open access archive for the deposit and dissemination of scientific research documents, whether they are published or not. The documents may come from teaching and research institutions in France or abroad, or from public or private research centers.
L'archive ouverte pluridisciplinaire HAL, est destinée au dépôt et à la diffusion de documents scientifiques de niveau recherche, publiés ou non, émanant des établissements d'enseignement et de recherche français ou étrangers, des laboratoires publics ou privés.

\section{(ㄷ)(1) $\$$}

Distributed under a Creative Commons Attribution - NonCommerciall 4.0 International 
Version of Record: https://www.sciencedirect.com/science/article/pii/S0141391018304154

Manuscript_056d56fadbea647cbe4257815f9d68d8

\title{
ABOUT THERMO-OXIDATIVE AGEING AT MODERATE TEMPERATURE OF CONVENTIONALLY VULCANIZED NATURAL RUBBER
}

\author{
François Grasland $^{\mathrm{a}}$, Laurent Chazeau ${ }^{\mathrm{a}}$, Jean-Marc Chenal ${ }^{\mathrm{a}, *}$, Regis $\operatorname{schach}^{\mathrm{b}}$ \\ ${ }^{a}$ Univ Lyon, INSA Lyon, CNRS, MATEIS UMR5510, F-69621, Lyon, France \\ ${ }^{\mathrm{b}}$ Centre de technologies, Manufacture Française des Pneumatiques Michelin, 63040 Clermont \\ Ferrand Cedex 9, France
}

*Correspondance email : jean-marc.chenal@insa-lyon.fr and laurent.chazeau@insa-lyon.fr

\begin{abstract}
This article is dedicated to the understanding of the mechanisms involved in the evolution of the structure of a "conventionally" vulcanized rubber during thermo-oxidative (TO) aging. Based on swelling measurements, WAXS and DSC, a scenario of these mechanisms is proposed. Our results show that the crosslinking reactions are far from being complete at the end of the vulcanization process. During TO aging carried out at a moderate temperature $77^{\circ} \mathrm{C}(350 \mathrm{~K})$, the creation of long bridges first takes place via the consumption of residual sulfur; this mechanism is mainly responsible of the increase in the density of elastically active chains. The presence of residual antioxidants inhibits in the early stages of aging the chemical reactions involving oxygen. For longer aging time (here 7 days), these reactions can then occur and create "unidentified" bridges whose formation may also involves sulfur grafted onto the polymer chains. Finally, all these cross-linking reactions seem to enhance the heterogeneity of the spatial distribution of the crosslinks - already existing in the initial material - and to create highly crosslinked domains.
\end{abstract}

Keywords : Natural Rubber, thermo-oxidative, ageing, vulcanization, network architecture

(C) 2019 published by Elsevier. This manuscript is made available under the CC BY NC user license https://creativecommons.org/licenses/by-nc/4.0/ 


\section{INTRODUCTION}

For most of its applications, Natural Rubber is submitted to a crosslinking reaction, which consists in the formation of bridges between the polymer chains. They are obtained through curing of the polymer blended with different ingredients. The most common recipe contains sulfur, which will form the bridges, and additives necessary to control the kinetics of the different involved crosslinking reactions. Among these additives, one distinguishes accelerator molecules. Their type and the ratio of sulfur to accelerator pilot the length distribution of the sulfur crosslinks. Networks rich in long polysulfidic crosslinks, called heafter Conventionnally Vulcanised NR (CV), obtained when this ratio is largely above 1, are said to provide better fatigue and tear resistance [1], [2] than networks rich in mono- and disulfide crosslinks. These ones, so called hereafter Efficiently Vulcanised NR (EV) system, are obtained when this ratio is below 1.

However, compared to EV systems, CV systems are said to have a lower resistance to ageing. Indeed, polysulfidic crosslinks should be thermally less stable than disulfide and monosulfide bridges [3]. When submitted to thermal ageing (anaerobic), depending on the temperature and the ageing time, non-reversible change can occur in the crosslink structure [4]-[7]. It leads for instance to a non-reversibility of the material deformation when this ageing is performed on a deformed material [8], [9]. When oxygen is also present, which is common in most applications, a reduction of the molecular weight of the elastomer through chain scissions (which can produce a decrease of the Young Modulus) is also observed [10], [11]. This reduces the strength properties and possibly adds nucleation sites for crack initiation and propagation. Oxidation can nevertheless also contribute to additional crosslinks formation [12]-[14], a behavior mainly depending on the matrix chemistry. Thus, thermo-oxidative ageing is the result of different mechanisms, whose consequences on the material properties can be contradictory, and strongly depend on the ageing temperature [12].

For tire application, the use temperature is below $80^{\circ} \mathrm{C}[15]-[17]$. The studies to understand these mechanisms are often performed at higher temperatures [7], [10], [18], [19]. Indeed, this choice enables to accelerate the processes. Nevertheless, the activation energies of the involved chemical reactions can be different [10], [20]. For this reason, accelerated ageing tests may induce erroneous lifetime prediction, especially in the case of $\mathrm{CV}$ systems where likely more mechanisms occur [12], [14]. Some studies display experimental results at low ageing 
temperatures for CV NR [8], [21]. However, to the knowledge of the authors, only Ahagon et al. [12], [14] independently analyzed thermal ageing and oxidative ageing, which can help to discriminate the chemical mechanisms involved. He reported that thermal ageing, performed below $80^{\circ} \mathrm{C}$ does not significantly change elastic active chains (EAC) density while oxidative ageing strongly increases it. All the samples studied were filled, but the possible influence of the fillers on the oxidation rate [22], [23] was not taken into account in the discussion, which hinders any definitive conclusion on the mechanisms involved in the matrix alone. Besides, using only mechanical tests, he could not dissociate them, neither he evaluated their different contribution. Thus, the aim of this paper is to go further in the understanding of the multi-steps thermo-oxidative ageing of $\mathrm{CV}$ system. To do so, model unfilled samples are processed and analyzed by combining rheological, DSC, WAXS and swelling measurements.

\section{EXPERIMENTAL}

\subsection{MATERIALS AND SAMPLES PROCESSING}

\begin{tabular}{|c|c|c|c|}
\hline Sample code & NR1.5 & NR2.5 & NR2.5_Eff \\
\hline $\mathrm{NR}^{\mathrm{a}}, \mathrm{phr}^{\mathrm{b}}$ & 100 & 100 & 100 \\
\hline $6 \mathrm{PPD}^{\mathrm{c}}, \mathrm{phr}$ & 3 & 3 & 3 \\
\hline Stearic Acid, phr & 2 & 2 & 2 \\
\hline Zinc Oxide, phr & 5 & 5 & 1.5 \\
\hline $\mathrm{CBS}^{\mathrm{d}}, \mathrm{phr}$ & 0.5 & 1 & 2.52 \\
\hline Sulfur, phr & 3 & 6 & 1.6 \\
\hline$v^{\mathrm{e}}\left(* 10^{-4} \mathrm{~mol} . \mathrm{cm}^{-3}\right)$ & 1.5 & 2.5 & 2.5 \\
\hline $\mathrm{t}_{98}, \min$ & 55 & 55 & 13 \\
\hline $\begin{array}{l}{ }^{\mathrm{a}} \text { Natural rubbe } \\
{ }^{\mathrm{b}} \text { Parts by weig } \\
{ }^{\mathrm{c}} \mathrm{N}-(1.3 \text {-dimetl } \\
{ }^{\mathrm{d}} \mathrm{N}-\mathrm{Cyclohexy} \\
\mathrm{e}^{\mathrm{e}} \mathrm{C} A \mathrm{C} \text {. }\end{array}$ & $\begin{array}{l}\text { ts of rub } \\
\text { yl-p-phe } \\
\text { sulfenan }\end{array}$ & & \\
\hline
\end{tabular}

Table 1: Samples recipes and initial EAC density

The materials are unfilled natural rubber, obtained by gum vulcanization (Technically Specified Rubber TSR20) according to the recipe given in Table 1. NR1.5 and NR2.5 have a Sulfur/CSB ratio of 6, i.e. above 1, leading to 
a network crosslinked mainly by polysulfidic bridges. In spite of different sulfur content, their same Sulfur/CBS ratio should ensure a same average length of the sulphur bridges. NR2.5_Eff with a Sulfur/CBS below 1 is crosslinked by an "efficient" recipe leading to a network mainly crosslinked by monosulfides bridges. First, the gum is introduced in an internal mixer and sheared at $50 \mathrm{rpm}$ for $2 \mathrm{~min}$ at $50{ }^{\circ} \mathrm{C}$. The material is subsequently sheared at $70 \mathrm{rpm}$ in an open mill for 5 minutes at $70{ }^{\circ} \mathrm{C}$. Then the vulcanization ingredients are added and the so-formed mixture is sheared for 5 minutes at $50^{\circ} \mathrm{C}$. Thin sample sheets $(0.8 \mathrm{~mm}$ thickness $)$ are finally obtained by hot pressing under nitrogen flux at $150^{\circ} \mathrm{C}$, for conventional system and $170^{\circ} \mathrm{C}$ for efficient system, $30 \mathrm{bars}$. The cure times were estimated from the torque measurements performed with a Monsanto analyzer as illustrated in Fig. 2. As usually, they are defined as the time needed to reach $98 \%$ of the maximum torque value $\left(t_{98}\right)$. It is worth mentioning that NR2.5 and NR2.5_Eff exhibit the same EAC density with different sulphur/CBS ratios, whereas NR1.5 and NR2.5 have a different EAC density with the same sulphur/CBS ratio.

\subsection{RHEOMETRY ANALYSIS}

Cure characterization was carried out with an Alphamodel ODR2000 oscillating disk rheometer in accordance with ASTM D2084-92. Evolution of torque has been followed on samples sheets $(2 \mathrm{~mm})$ at $150^{\circ} \mathrm{C}$ from 0 to 100 minutes. Results were provided by Michelin Company.

\subsection{DSC ANALYSIS}

DSC data were acquired using a Pyris Diamond calorimeter (Perkin Elmer, U.S.A) beforehand calibrated with an indium standard. The samples weight was $10 \mathrm{mg}$ encapsulated in an aluminum pan. They were heated from 20 to $150^{\circ} \mathrm{C}$ at $50^{\circ} \mathrm{C} \cdot \mathrm{min}^{-1}$. Measurements are performed when the samples are maintained at $150^{\circ} \mathrm{C}, 160$ min in order to follow the vulcanization process. This one is evidenced by the appearance of an exothermic peak on the thermogram (cf. Fig. S2 in SI). Then, samples were quenched at $20^{\circ} \mathrm{C}$ and submitted again to the same thermal program to ensure the end of curing. The DSC thermogram obtained during this second isothermal treatment at $150^{\circ} \mathrm{C}$ provides the baseline needed to calculate the previous peak enthalpy.

\subsection{WAXS ANALYSIS}

Wide-Angle X-ray scattering measurements were carried out on an apparatus equipped with a copper rotating anode $(\lambda=1.54 \AA$ A $)$ (Rigaku Corporation, Japan), Gobel's mirrors collimation system 160 (Elexience, France) and a 2D detector (CCD camera from Princeton Instruments, USA). The acquisition time of the diffraction pattern is 
5 min. Each pattern was integrated azimuthally and corrected from the background scattering. The corrected scattering intensity was normalized by the thickness and the absorption of each sample. The deconvolution of the curve $I=f(2 \theta)$ was performed using Lorentzians functions (cf. Fig. S1) in order to extract the ZnS peak. This method was used to follow the evolution of the $\mathrm{ZnS}$ peak area during the vulcanization process.

\subsection{AGEING CONDITIONS}

All materials were submitted to thermo-oxidative (TO) and thermal ageing at $77^{\circ} \mathrm{C}$ from 0 to 21 days. To fulfill thermal conditions (absence of oxygen), the samples were first submitted to a degassing step. This specific protocol used an home-made device and a succession of 3 steps described in Fig. 1.

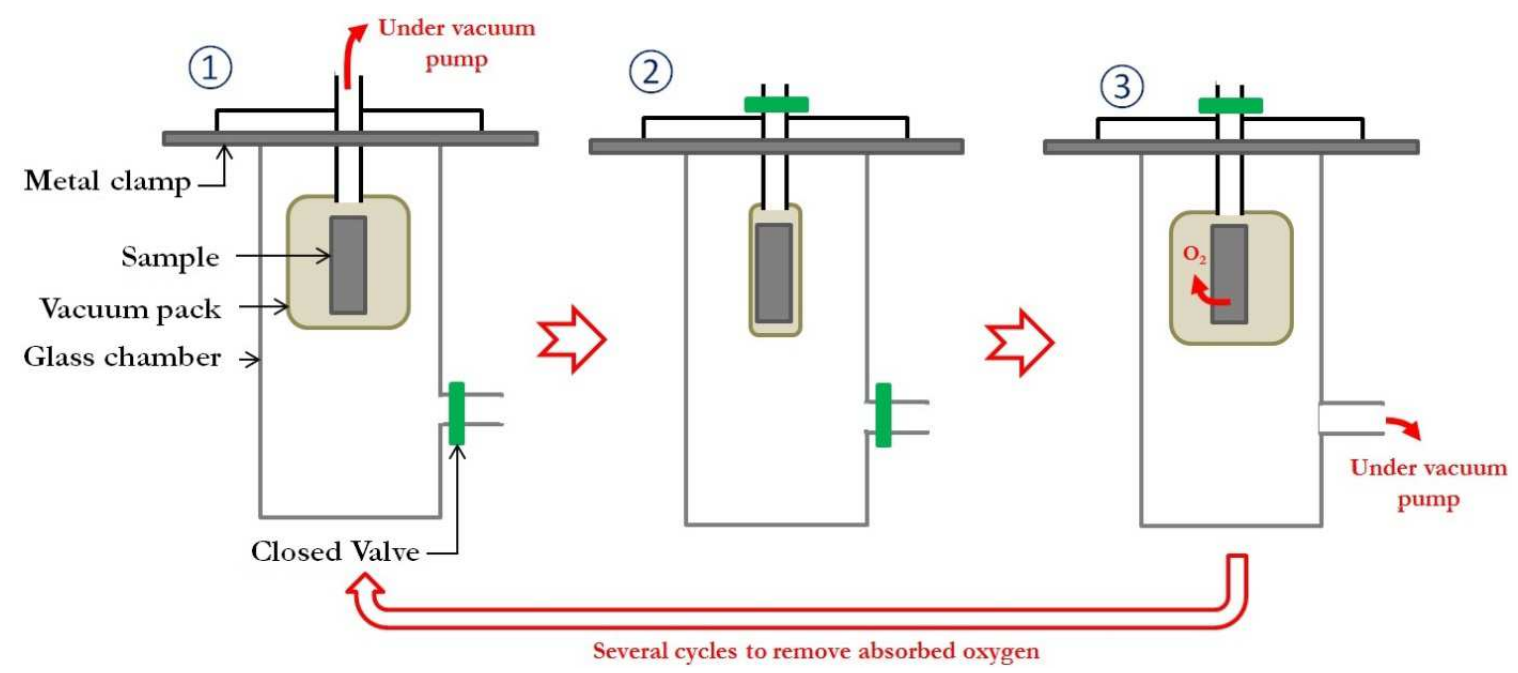

Fig. 1: Schematical view of the under vacuum device and the procedure to remove oxygen from the sample.

The samples are sealed in a multilayer envelop (aluminum + cardboard) impermeable to air. They are put in a dedicated system made of two chambers. First, the vacuum pump extracts the air from the vacuum pack (Step (1)), then the valve of this pack is closed (Step (2)). Afterwards the vacuum is made inside the glass chamber (Step (3). At the end of the third step, the vacuum pack swells due to desorption of air from the sample. These three steps are repeated until the swelling of the vacuum pack becomes unnoticeable, indicating a total gas desorption. Finally, the vacuum pack is sealed before returning to atmospheric pressure. When not tested, all the samples are then stored at $7^{\circ} \mathrm{C}$ to avoid any degradation. When tested, they are first maintained at $60^{\circ} \mathrm{C}$ during 5 min to avoid any presence of crystallites.

\subsection{SWELLING MEASUREMENTS}


Swelling measurement provides elastomer network chain density (from the swelling ratio $Q$ ) and the fraction of the chains and soluble species that does not belong to the elastically active network (from the soluble fraction $F_{s}$ ). The swelling procedure is as follows: samples with an initial mass $m_{i}$ is introduced in the solvent (these experiments are performed with toluene and cyclohexane) for 5 days in order to reach the swelling equilibrium at room temperature. Then, the swollen material having a weight $m_{s}$ is dried under vacuum at $50{ }^{\circ} \mathrm{C}$ during one day resulting in a final sample mass $m_{d}$. The swelling ratio $Q$ of the polymer and the soluble fraction $F_{s}$ are then calculated through the Eq. 1 and 2:

$$
\begin{aligned}
& \mathrm{Q}=\frac{1}{\mathrm{~V}_{2}}=1+\frac{\rho_{\mathrm{p}}}{\rho_{\mathrm{s}}} \times\left(\frac{\mathrm{m}_{\mathrm{s}}}{\mathrm{m}_{\mathrm{d}}}-1\right) \\
& \mathrm{F}_{\mathrm{s}}=100 \times\left(\frac{\mathrm{m}_{\mathrm{i}}-\mathrm{m}_{\mathrm{d}}}{\mathrm{m}_{\mathrm{i}}}\right)
\end{aligned}
$$

Where $\rho_{p}$ and $\rho_{s}$ correspond to the density in g.cm ${ }^{-3}$ of the polymer and the solvent respectively ( 0.92 for natural rubber, 0.87 for toluene and 0.78 for cyclohexane). From the volume fraction $V_{2}$ of polymer in the swollen mass (inverse of $Q$ ), the elastic active chain (EAC) density $v_{\text {swelling }}$ is estimated using the Flory-Rehner equation [24]. $v_{\text {swelling }}$ is the result of two contributions: EAC created by trapped entanglements and by the chemicals crosslinks formed during the vulcanization process:

$$
v_{\text {swelling }}=-\frac{\left[\ln \left(1-V_{2}\right)+V_{2}+\chi * V_{2}\right]}{V_{1} *\left(V_{2}^{\frac{1}{3}}-2 * \frac{V_{2}}{f}\right)}
$$

Where $\chi$ the Flory-Huggins interaction parameter is $V_{1}$ is the molar volume of the solvent $\left(107.9 \mathrm{~cm}^{3} . \mathrm{mol}^{-1}\right.$ for cyclohexane and $106.3 \mathrm{~cm}^{3} \cdot \mathrm{mol}^{-1}$ for toluene) and $f$ is the crosslink functionality. The low soluble fraction of the processed material (below 5\% weight, this fraction being mainly curative residuals) suggests that most chains belong to the rubber network; thus $f$ can be taken equal to 4 . As recently mentioned by Valentin et al, the Flory- 
Huggins interaction parameter $\chi$ has a strong impact on the calculated $v_{\text {swelling }}$ [25]. A widely used equation to estimate this parameter is based on the Hildebrand solubility constants:

$\chi=\chi_{\mathrm{s}}+\frac{\mathrm{V}_{1}}{\mathrm{RT}}\left(\delta_{\mathrm{s}}-\delta_{\mathrm{p}}\right)^{2}$

Where $\delta_{s}$ and $\delta_{p}$ are the solubility parameters for solvent and polymer respectively, $R$ the ideal gas constant and $T$ the absolute temperature. The first factor $\chi_{s}$ is an entropic contribution and was found empirically equal to 0.34 for non-polar systems [26]. During thermo-oxidative ageing, oxygen modifies the chemical nature of the elastomer network by oxidation (i.e. there is formation of polar functions on the chains). Thus, the chemical affinity between the solvent and the polymer and therefore the value of the interaction parameter $\chi$ changes. Considering that the concentration of elastically active chains $v_{\text {swelling }}$ is identical regardless of the nature of the good solvent used, the observation of different swelling ratio with different solvent is inevitably linked to a modification of $\chi$ (and $\delta_{p}$ ). Thus, swelling measurements with two good solvents make possible the estimation of the solubility parameter of the polymer $\delta_{p}$ via Eq. 4 . The calculations associated with these measurements are detailed in the SI (cf. S6).

\subsection{THERMOPOROSIMETRY}

Thermoporosimetry is a characterization techniques used to measure the distribution of pore size in porous material from calorimetry measurements. This is based on the modification of the solvent melting temperature by its confinement in the pores. In swelled crosslinked network, a phase segregation in small domains is observed during cooling. Like in porous materials, the idea is that the size of the segregated domains is related to the space available for this segregation, in other words to the local extensibility of the chains around the domain. Thus, this size is related to the local active chain density. The samples were swollen in hexadecane, which is the best solvent for this experiment, as its crystallization can be complete [27]. They were then introduced into an aluminum pan. The DSC apparatus was a Perkin-Elmer Pyris Diamond. The samples were first cooled at $1{ }^{\circ} \mathrm{C} /$ minute from $25^{\circ} \mathrm{C}$ to $-10^{\circ} \mathrm{C}$, and then maintained at $-10^{\circ} \mathrm{C}$ for 5 minutes. They were then heated at $1^{\circ} \mathrm{C} /$ minute to $25^{\circ} \mathrm{C}$. While increasing temperature from $-10^{\circ} \mathrm{C}$ to $25^{\circ} \mathrm{C}$, a peak is first observed corresponding to the melting of the hexadecane domains crystallized in the network. The largest this melting temperature, the largest are the related melting domains (following the Gibbs Thomson description). The first melting peak is followed at around $19^{\circ} \mathrm{C}$ by a second, much sharper peak corresponding to the melting of the free hexadecane. The signal is normalized by the mass of dried sample. 


\subsection{DYNAMIC MECHANICAL ANALYSIS}

DMA measurements were carried out on a homemade torsional pendulum previously detailed [28]. This apparatus measures the values of the real and imaginary parts of the shear modulus (storage modulus G' and loss modulus G”). Parallelepiped samples (Length*Width*Thickness: $30^{*} 6^{*} 0.8 \mathrm{~mm}^{3}$ ) were tested. The sample chamber was filled with inert gas (helium at $600 \mathrm{mbar}$ ) and the measurements were performed between $200 \mathrm{~K}$ and $320^{\circ} \mathrm{K}$ at a heating rate of $1^{\circ} \mathrm{C} \cdot \mathrm{min}^{-1}$ and a strain frequency of $1 \mathrm{~Hz}$.

\subsection{RESIDUAL CONCENTRATION OF ANTI-OXIDANTS (6PPD)}

Residual concentration of anti-oxidants was measured using HPLC and ultraviolet absorption spectrum. Results were provided by Michelin Company only for non-aged and aged NR2.5. 


\section{RESULTS}

\subsection{VULCANIZATION AT $150^{\circ} \mathrm{C}$}

Fig. 2 shows the evolutions of $v_{\text {swelling }}$ and torque for NR2.5 and NR1.5 during the vulcanization process at $150^{\circ} \mathrm{C}$. As expected, the maximum torque increases with the sulfur content. Moreover, similar evolutions are observed for $v_{\text {swelling }}$ and torque as a function of cure time for both materials. These parameters continually increase during vulcanization until optimal mechanical properties are reached after $t_{98}=55$ minutes. Beyond this time, EAC densities and torque weakly decrease. This behaviour has been ascribed to the cleavage of polysulfidic crosslinks. This decreases the crosslink density and therefore the EAC density [6]. At $t_{98}$, average EAC densities of NR1.5 and NR2.5 are found equal to $1.5 * 10^{-4}$ and $2.5 * 10^{-4}$ mol.cm $\mathrm{cm}^{-3}$ respectively.

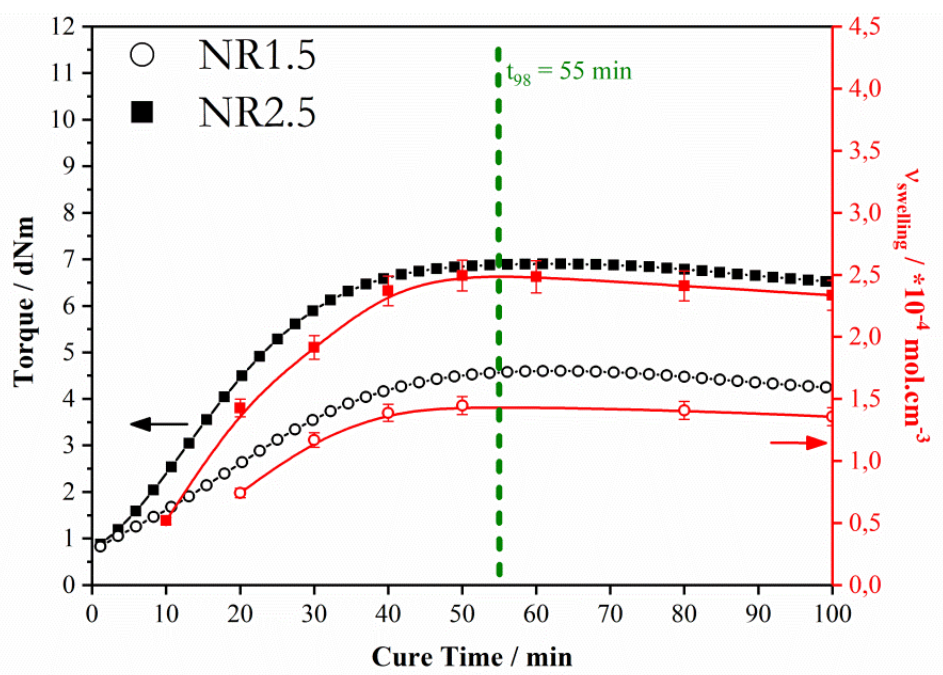

Fig. 2 : Torque and EAC density as a function of cure time at $150^{\circ} \mathrm{C}$ - Lines are plotted as a guide for the eyes.

The progress of the vulcanization reactions is generally associated with the conversion of the crosslinks precursors (i.e. active sulfurating agent) into crosslinks. According to the generally accepted - and simplified theory of accelerated sulfur vulcanization (cf. Fig. 3) : the first step (1) in the reaction sequence involves interaction between the accelerator (CBS), $\mathrm{ZnO}$ and a ligand (stearic acid and/or an amine, like cyclohexylamine freed by CBS decomposition) to form an accelerator-zinc complex [6][29], [30]. Then the latter is assumed to react with free sulfur $S_{8}(2)$ to form an active sulfurating agent with variable $S_{a}$ and $S_{b}$ arm lengths: the higher the S/CBS ratio, the longer these arms, and consequently the sulfur bridges finally created. 

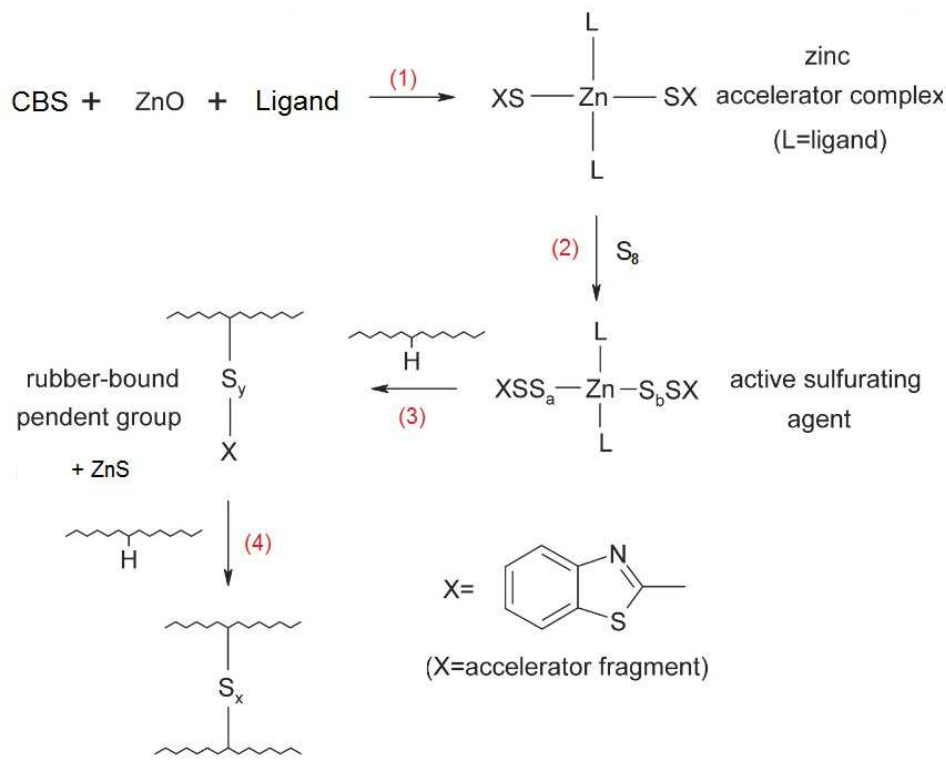

Fig. 3 : Chemical mechanisms involved during the accelerated vulcanization process [30]

This $\mathrm{Zn}$ species is found at an early stage of vulcanization and is likely to react with a carbon-carbon double bond (3) forming a polysulfidic pendant group along the polymer chain, and a new complex which may react with this newly formed pendant group and help it link (4) with another $\mathrm{C}=\mathrm{C}$ bond, and thus finalize the desired crosslink (either active or inactive). Following this scheme, it will eventually produce some ZnS byproduct : at first sight, formation of two crosslinks, i.e. two polysulfidic bridges during vulcanization process should be indirectly associated to the formation of one $\mathrm{ZnS}$ molecule. Nevertheless, the authors acknowledge that the mechanical scheme is far from being clearly understood, as demonstrated by new evidences from litterature which suggests for exemple that the $\mathrm{Zn}$ complex may be a bimetallic one with a 1:1 ratio between $\mathrm{Zn}$ and the created pendent groups [31]. Anyhow, looking at the relative $\mathrm{ZnS}$ content evolution through the vulcanizing process remains interesting as a potential ongoing vulcanization marker when one follows its characteristic peak $\left(2 \theta=27^{\circ}[32],[33]\right)$ through WAXS measurements (cf. Fig. 4a). We define the following $\xi_{\text {waxs }}$ index:

$\xi_{\text {WAXS }}(\%)=\frac{A_{\text {ZnS Peak }}(t)}{A_{\text {ZnS Peak }}\left(t_{\infty}\right)}$

Where $A_{Z n S \text { Peak }}(t)$ is the $\mathrm{ZnS}$ peak area of compound cured for a time $t$, and $A_{Z n S ~ P e a k}\left(t_{\infty}\right)$ the $Z n S$ peak area for the same compound in which all the chemicals reactions producing $\mathrm{ZnS}$ molecules are assumed to be finished 
(i.e. when the peak does not evolve anymore with time). $\xi_{\text {WAXS }}$ is plotted as a function of the curing time in Fig.

4b.
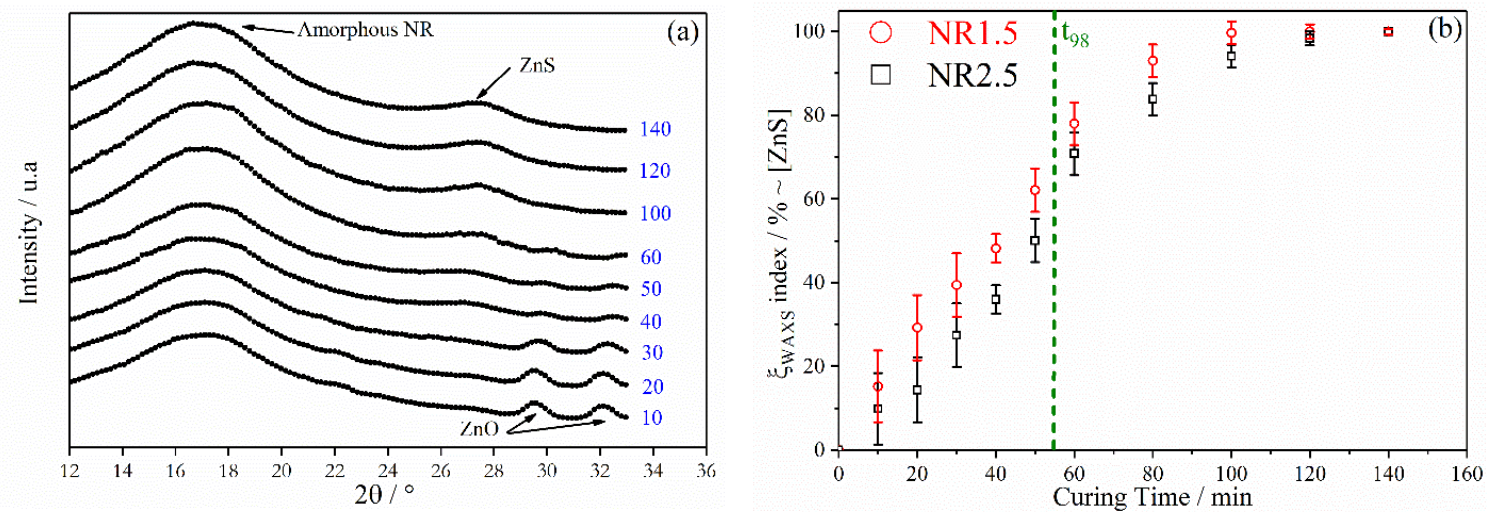

Fig. 4 : (a) Evolution of $\mathrm{ZnS}$ and $\mathrm{ZnO}$ peaks for NR2.5 along the vulcanization process (In blue : Curing time in min) (b) $\xi_{\text {WAXS }}$ as a function of curing time at $150^{\circ} \mathrm{C}$.
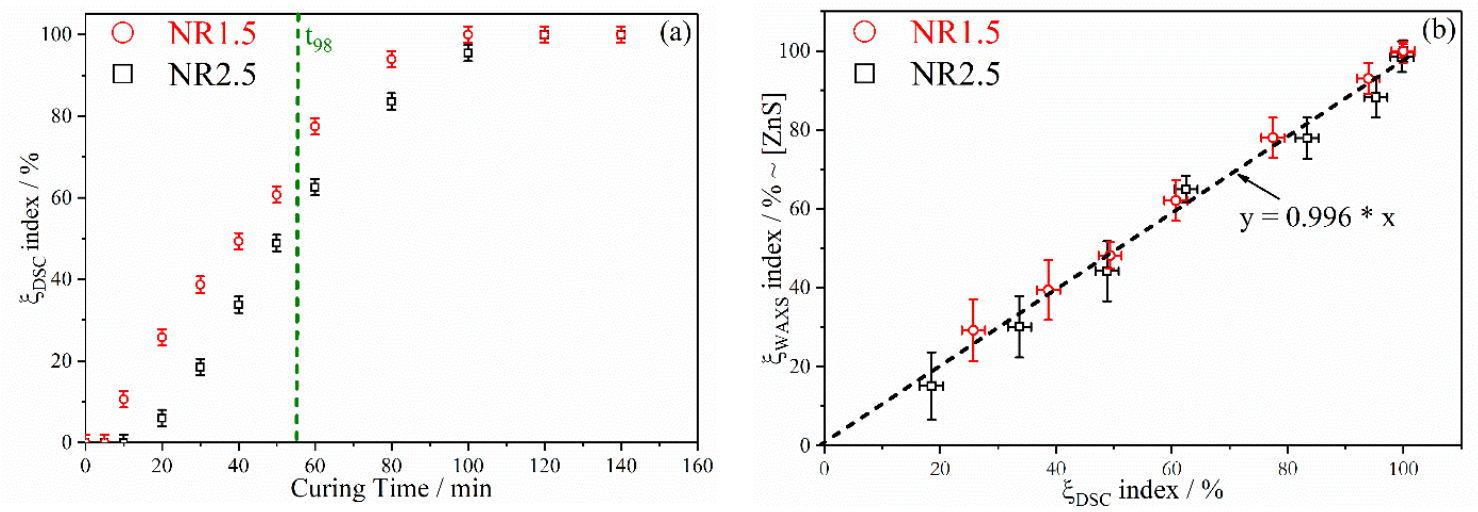

Fig. 5 : (a) $\xi_{\text {DSC }}$ as a functioned of Curing time at $150^{\circ} \mathrm{C}$ (b) $\xi_{\text {DSC }}$ as a function of $\xi_{\text {WAXS }}$. The dashed line is a linear fit.

Isothermal DSC measurements were recorded a $150^{\circ} \mathrm{C}$ as a function of time for an uncured compounded rubber. All involved reactions are exothermic $(\Delta \mathrm{H}$, enthalpy); the observed exotherm depends on the nature of the polymer, curatives and other additives in the matrix [34], [35] (Fig. S2). Its evolution is associated with the progress of all the chemicals reactions involved during the vulcanization process. It can be followed through the index:

$\xi_{\mathrm{DSC}}(\%)=\frac{\Delta \mathrm{H}(\mathrm{t})}{\Delta \mathrm{H}\left(\mathrm{t}_{\infty}\right)}$ 
Where $\Delta H(t)$ is the enthalpy of the compound cured for time $t$ and $\Delta H\left(t_{\infty}\right)$, the total enthalpy for which all the chemicals events are finished (estimated when $\Delta \mathrm{H}(\mathrm{t})$ is stabilized). $\xi_{\mathrm{DSC}}$ is plotted as a function of the curing time and of $\xi_{\text {WAXS }}$ in Fig. 5a and $5 \mathrm{~b}$ respectively. The evolution of $\xi_{\text {DSC }}$ with time is consistent with the one observed for $\chi_{\text {waxs }}$ in Figure $5 \mathrm{~b}$. A linear dependency is found between both indexes indicating that $\mathrm{ZnS}$ could be considered as a probe of the vulcanisation progress. Additionally, $\xi_{\mathrm{WAXs}}$, i.e the $\mathrm{ZnS}$ content, still increases beyond $t_{98}$ for both materials. Such finding is unexpected and indicates that the optimal mechanicals properties (i.e. the maximum EAC density measured at $\mathrm{t}_{98}$ ) may not correspond to the end of the crosslinking process.

\subsection{AGEING AT $77^{\circ} \mathrm{C}$}

Once cured at $\mathrm{t}_{98}$, the materials have been aged from 0 to 21 days at $77^{\circ} \mathrm{C}$, in thermal (no oxygen), and thermooxidative conditions (so called $\mathrm{TH}$ ad $\mathrm{TO}$ conditions respectively).

\subsubsection{THERMAL AGEING}

Dashed lines on Fig. 6 report the evolution of the EAC densities during TH ageing from 0 to 21 days for NR2.5, NR1.5 and NR2.5_Eff. At 7 days, conventionally crosslinked rubbers display an increase of $v_{\text {swelling }}$ while no evolution is noticed for NR2.5_Eff. Variation of EAC density is more important for NR2.5 (+ $32 \%)$ compared

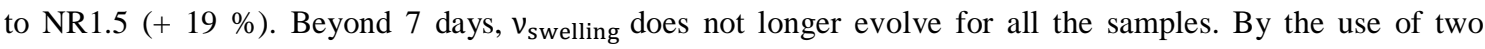
solvents (cyclohexane and toluene) and of Eq. 4 (Calculation presented in S6), the solubility parameter of the polymer $\delta_{\mathrm{p}}$ can be deduced and indirectly provides an estimate of the evolution of the polar component of our samples. Fig. 7 displays its evolution as a function of the ageing duration. As expected, $\delta_{\mathrm{p}}$ is found constant, which is consistent with the fact that no oxygen is involved in the chemical reactions occurring during $\mathrm{TH}$ ageing of NR1.5 and NR2.5.

\subsubsection{THERMO-OXIDATIVE AGEING}

Evolutions of EAC densities during TO ageing (solid lines) are compared to the ones obtained during thermal ageing (dashed lines) in Fig. 6. For NR1.5 and NR2.5, the curves superimpose between 0 and 7 ageing days.

Meanwhile, $\delta_{\mathrm{p}}$ stays roughly constant (cf. Fig. 7a). These similar trends for $v$ and $\delta_{\mathrm{p}}$ are quite unexpected, as oxidative mechanisms should normally take place. An explanation may be that during these first 7 days, oxygen 
is consumed by the residual antioxidants (6PPD, used to hinder oxidative reactions [18],[29]) unconsumed during the vulcanization process.

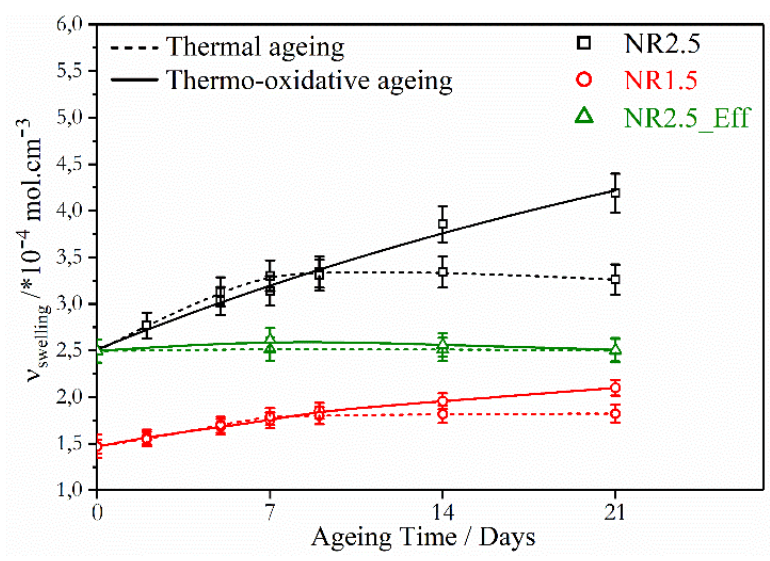

Fig. 6 : EAC density versus ageing time at $77^{\circ} \mathrm{C}$ - Lines are plotted as a guide for the eyes
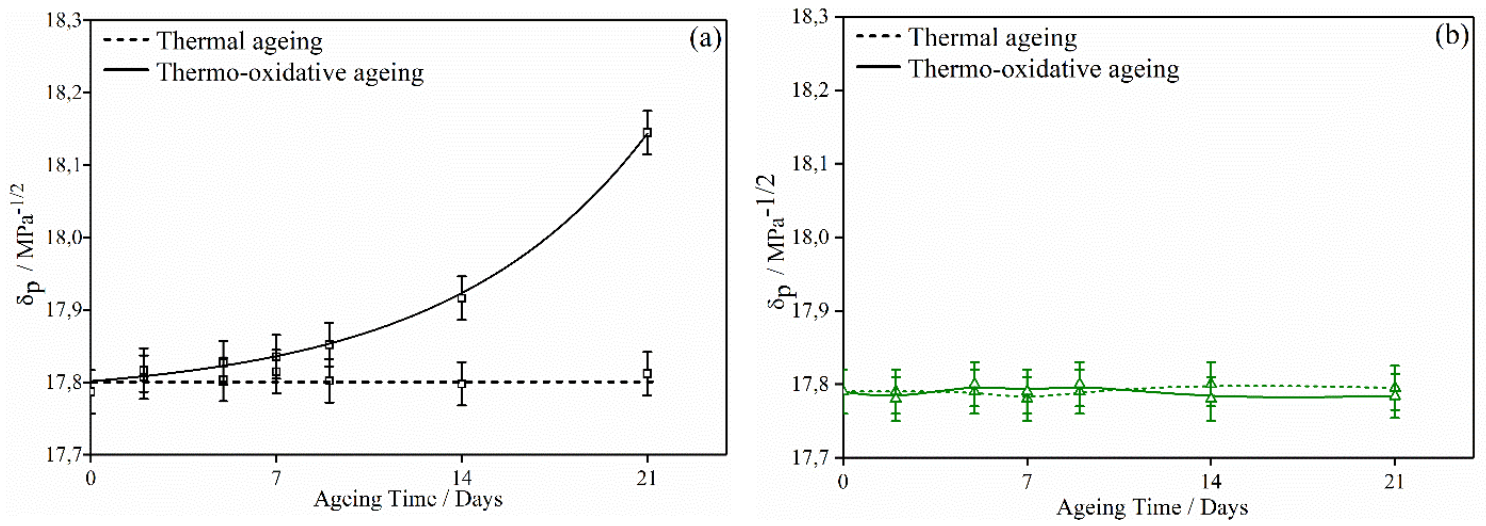

Fig. 7 : Solubility parameter of (a) NR2.5 and (b) NR2.5_Eff as a function of ageing time at $77^{\circ} \mathrm{C}-$ Lines are plotted as a guide for eyes

\begin{tabular}{|c|c|c|c|}
\hline TO ageing time & 0 day & 7 days & 14 days \\
\hline NR2.5 previously TO aged 7 days & 3.1 & 3.9 & 4.2 \\
\hline NR2.5 previously TH aged 7 days & 3.1 & 3.1 & 3.9 \\
\hline
\end{tabular}

Table $2: v_{\text {swelling }}\left(* 10^{-4}\right.$ mol.cm $\left.{ }^{-3}\right)$ for NR2.5, as a function of TO ageing time 
To address this question, a specific study was performed on the most crosslinked sample NR2.5. It was first thermally aged for 7 days at $77^{\circ} \mathrm{C}$, during which residual anti-oxidant should be not consumed. Then, it was aged for additional 7 days and 14 days, in presence of oxygen. The sample EAC densities deduced from swelling measurements are presented in Table 2. EAC density of the sample previously thermally aged during 7 days is constant during the following 7 days of TO ageing. Then it increases again to reach, at 14 days of TO ageing, the value obtained when the sample is only submitted to TO ageing during 14 days (In other words, there is a shift of the EAC((time) curve). Additionally, some experiments were performed to measure the concentration of residual anti-oxidants after TO ageing (cf. Fig. 8). As expected, residual antioxidants are still present after vulcanization. Their concentration rapidly decreases during the first 7 days and much slowly the following days. This confirms our assumption that the apparent similarity between TO and TH ageing during the first 7 days is due to the initial presence of antioxidant in the sample, whose consumption prevents the oxygen from playing a role in the degradation mechanisms. This explanation should also be valid for NR1.5 if one makes the reasonable assumption that the remaining quantity of antioxidant after vulcanization is the same as in NR2.5 (reasonable as the initial 6PPD quantity and the curing time are the same).

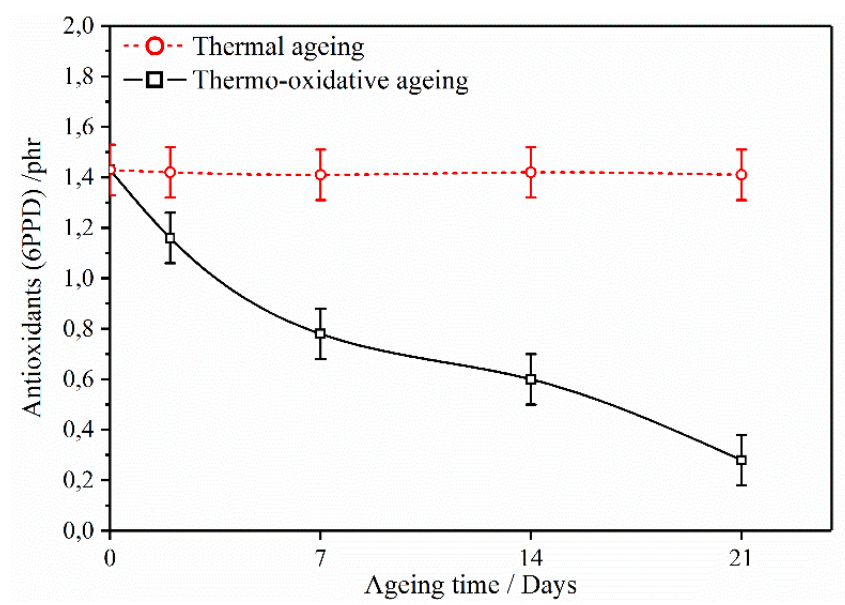

Fig. 8 : Concentration of residual antioxidants after $\mathrm{TH}$ and $\mathrm{TO}$ ageing at $77^{\circ} \mathrm{C}$ for $\mathrm{NR} 2.5$ - Lines are plotted as a guide for the eyes

For TO ageing longer than 7 days, $\delta_{\mathrm{p}}$ (cf. Fig. 7) and EAC densities (cf. Fig. 6) increase for NR2.5 and NR1.5 whereas they remain both constants for NR2.5_Eff. Such finding suggests that presence of oxygen in conventionally crosslinked rubbers leads simultaneously to supplementary crosslinking and to the formation of polar groups. Note that, after 21 days TO ageing, the $\delta_{\mathrm{p}}$ variation is the same for NR1.5 and NR2.5, whereas the EAC density evolution is twice higher for NR2.5 (+ 33\%) than for NR1.5 (+ 18\%). 
Competitive processes should be involved here: chain scissions, chain crosslinking and possibly sulfur bridges reorganization/scission. The consequences of chains crosslinking predominates for NR1.5 and NR2.5 (cf. Fig. 6). Constant weight soluble fractions, around 5\% (results presented in S3) means that scissions are not numerous enough to create supplementary free chains. Nevertheless, a significant amount of scission occurs as TO ageing at $77^{\circ} \mathrm{C}$ of pure isoprene rubber (no vulcanization system) leads to a decrease of its $\mathrm{M}_{\mathrm{n}}$ (cf. Fig. 9a).
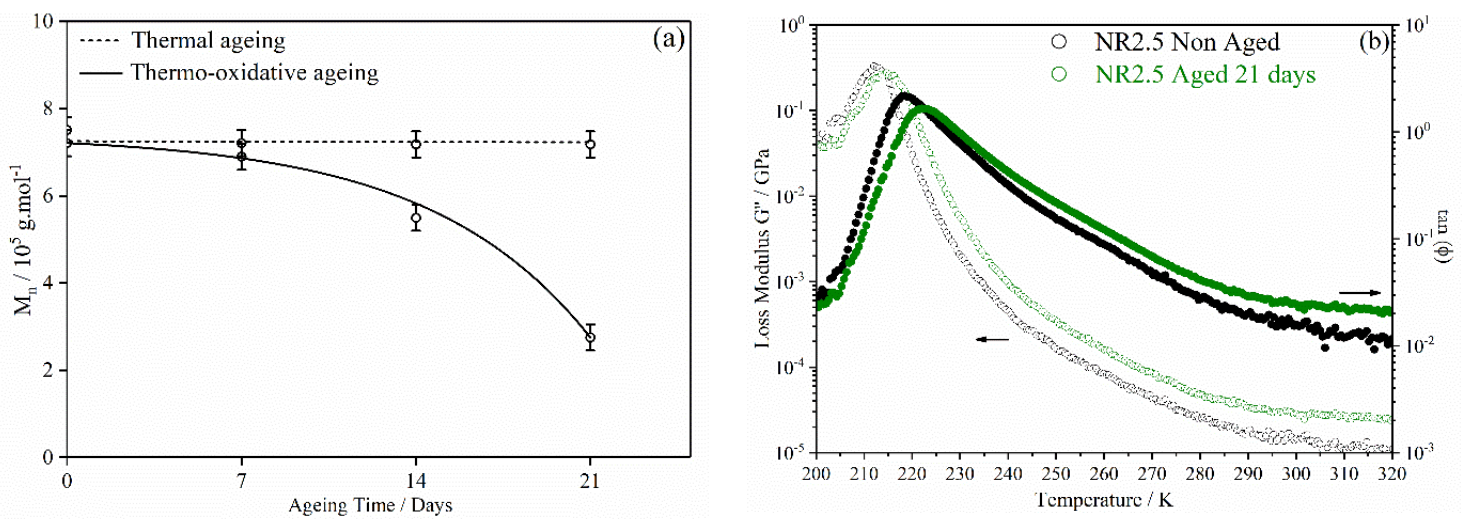

Fig. 9 : (a) Average molar mass of the non-vulcanized isoprene rubber during thermal ageing (dash line) and thermo-oxidative ageing (solid line) at $77^{\circ} \mathrm{C}$ - Lines are plotted as a guide for the eyes

(b) Loss modulus $G^{\prime \prime}$ (filled dots) and $\tan (\varphi)$ (unfilled dots) as a function of temperature for non-aged and thermo-oxidative aged NR2.5 ( $\mathrm{f}=0.1 \mathrm{~Hz}, \gamma$ below 0.001$)$.

Consequently, TO ageing necessarily leads to the formation of dangling chains in the aged rubber network. This is evidenced by the increase in $\mathrm{G}^{\prime \prime}$ and $\tan (\phi)$, measured in the rubbery plateau, with the ageing time increase (cf. Fig. 9b). Fig. 9a indicates that 21 days of TO ageing should lead to around a maximum of $0.36^{*} 10^{-5}$ mol.g ${ }^{-1}$ of chain scissions ("maximum" as the presence of vulcanisation system may decrease the number of chain scissions in the elastomer). Considering NR1.5, the less initially crosslinked material, its EAC density increase is around $0.27 * 10^{-4}$ mol.g ${ }^{-1}$ after 21 days of TO ageing. This is much larger than the previous chains scissions estimate $(\approx$ at least 10 times lower $)$ and suggests that these scissions can be considered as negligible compared to crosslinking.

$\xi_{\text {WAXS }}$ is plotted as a function of ageing time in Fig. 10. First, it is worth recalling that at $\mathrm{t}_{98}$, the $\mathrm{ZnS}$ initial concentration is not the maximum one : $\xi_{\text {WAXS }}$ is equal to 0.71 for NR1.5 and to 0.60 for NR2.5. More importantly, $\xi_{\text {WAXs }}$ does not evolve from 0 to 21 days which suggests that the $\mathrm{Zn}$ species involved in the 
vulcanization mechanism illustrated in Fig. 3 are not involved in the EAC density increase at $77^{\circ} \mathrm{C}$ (cf. Fig. 6). It means that a different crosslinking mechanism should take place during this ageing time at $77^{\circ} \mathrm{C}$.

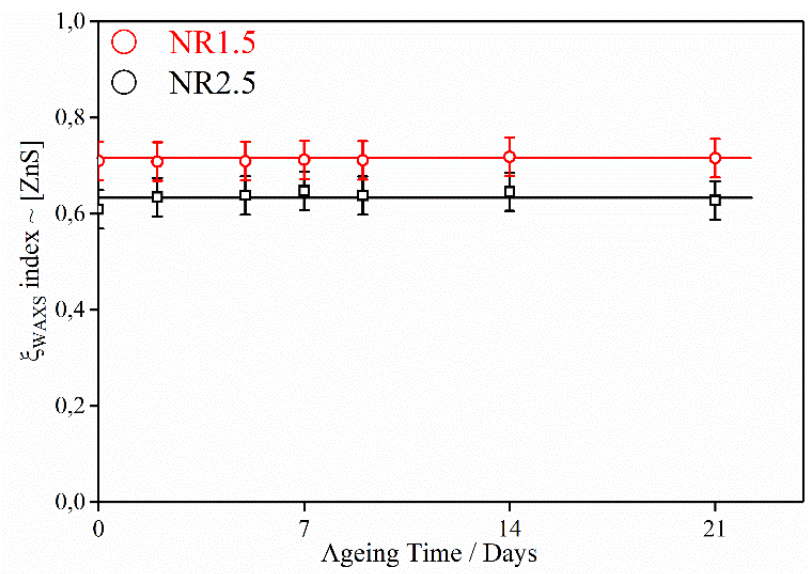

Figure $10: \xi_{\text {WAXs }}$ as a function of the ageing time measured during TO ageing at $77^{\circ} \mathrm{C}$ from 0 to 21 days - Lines are plotted as a guide for the eyes

\subsubsection{STABILITY OF THE NEW BRIDGES FORMED DURING AGEING}
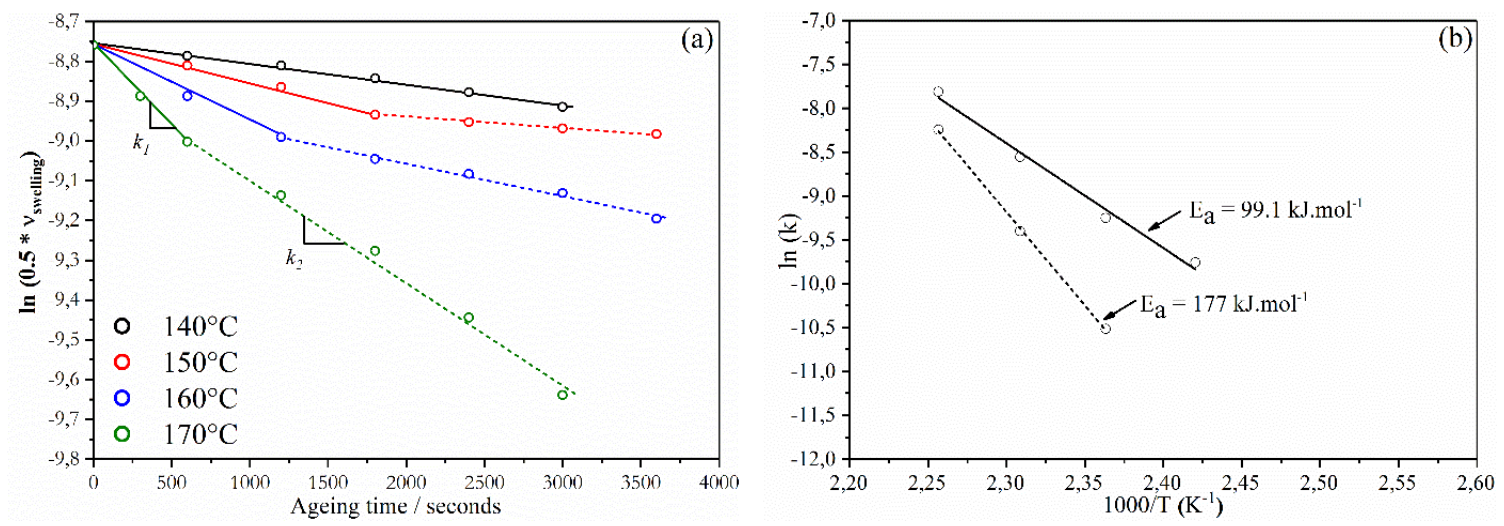

Fig. 11 : (a) $\ln$ (Crosslink density) versus thermal ageing time for different ageing temperature for NR2.5 previously $\mathrm{TO}$ aged at $77^{\circ} \mathrm{C}$ for 7 days (b) Arrhenius plot and the deduced thermal activation energy

Evolution of the crosslinks density is studied during TH ageing for a previously 7days-TO aged NR2.5. The temperature chosen for this experiment are $140^{\circ} \mathrm{C}, 150^{\circ} \mathrm{C}, 160{ }^{\circ} \mathrm{C}$, and $170{ }^{\circ} \mathrm{C}$, i.e. consistent with curing temperature. In this temperature range, it is known that polysulfidic crosslinks dissociate and form mostly nonelastically active sulfur chains while di or mono-sulfides are relatively stable [3],[12]. Indeed, sulfur bridges of lengths greater than 4 are more easily broken owing to their lower bond dissociation energies of $150 \mathrm{~kJ} / \mathrm{mol}$ [36]. Conversely, decomposition of di- and monosulfide bridges are more difficult due to their higher dissociation 
energy, which are 270 and $320 \mathrm{~kJ}^{-\mathrm{mol}^{-1}}$ respectively [37], [38]. Considering that thermolytic chain scission is not involved during thermal ageing up to $170^{\circ} \mathrm{C}$ along the polymer backbone [8][30] (and assuming that this is also true in presence of sulfur species), variations of the crosslinks density are mainly due to the destruction of sulfur bridges. Assuming a first order kinetic, the concentration of [S-S] bridges may be expressed as :

$[\mathrm{S}-\mathrm{S}]=[\mathrm{S}-\mathrm{S}]_{0} * \exp (-\mathrm{kt})$

Where $\mathrm{k}$ is the rate constant in $\mathrm{s}^{-1}$. As shown by Fig. 11a, two regimes are highlighted by these experiments and the transition between both regimes occurs, whatever the ageing temperature, when crosslink density has roughly decreased by around $7 * 10^{-5}$ mol.cm ${ }^{-3}$, i.e. when the crosslink density of the sample has returned to the value of the non-aged sample. From these results, two scissions constant rates $\mathrm{k}_{1}$ and $\mathrm{k}_{2}$, corresponding to these regimes, can be deduced, as a function of temperatures (from $140^{\circ} \mathrm{C}$ to $170{ }^{\circ} \mathrm{C}$ ). Arrhenius extrapolation assumes that a reaction rate $\mathrm{k}$ is proportional to $\exp \left(-\mathrm{E}_{\mathrm{a}} / \mathrm{RT}\right)$, where $\mathrm{E}_{\mathrm{a}}$ is the Arrhenius activation energy, $\mathrm{R}$ the gas constant $\left(8.314 \mathrm{~J} / \mathrm{mol}_{\mathrm{K}} \mathrm{K}^{-1}\right), \mathrm{T}$ the absolute temperature and A the pre-exponential factor [14], [40] :

$\mathrm{k}=\mathrm{Ae}^{-\mathrm{E}_{\mathrm{a}} / \mathrm{RT}}$

Arrhenius plots give two straight lines for $k_{1}$ and $k_{2}$ (with a correlation coefficient $\mathrm{R}^{2}=0.992$ ) whose slope corresponds to activation energies of $99.1 \mathrm{~kJ} \mathrm{~mol}^{-1}$ and $177 \mathrm{~kJ} \cdot \mathrm{mol}^{-1}$ (Fig. 11b). Such result indicates the successive destruction of two different sulfur networks in NR2.5. Indeed, the former value is found lower than bond dissociation energy typically found for length much larger than 4 [36] while the latter corresponds to dissociation energy of sulfur bridges of length around 4 [37], [38]. Thus, the first bridges destroyed during the post curing of the aged sample should corresponds to long polysulfur bridges. The variation of the EAC density due to this destruction, obtained after 30 minutes at $150^{\circ} \mathrm{C}$, is around three times larger than the EAC decrease observed when the initial material is cured 30 min more than $t_{98}$. This indicates that the majority of these long polysulfur bridges have been created during the material ageing at $77^{\circ} \mathrm{C}$.

\section{DISCUSSIONS}


From the previous results, let us now discuss the network structure evolution of conventionally crosslinked rubber during $\mathrm{TO}$ ageing at $77^{\circ} \mathrm{C}$ (up to 21 days). Assuming that $\mathrm{ZnS}$ is a probe of the sulfur bridges concentration during curing, we have plotted EAC density as the function of $\xi_{W A X S}$ (i.e ZnS) in Fig. 12 for different curing times, from 0 to 100 minutes at $150^{\circ} \mathrm{C}$.

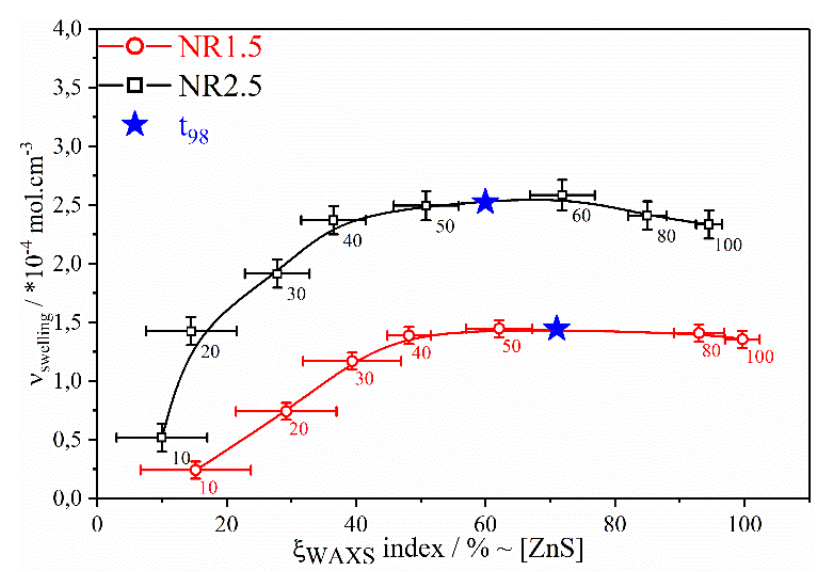

Fig. 12 : EAC density as a function of $\xi_{\text {WAXs }}$ at $150^{\circ} \mathrm{C}$. Curing time in minutes is indicated for each data points Lines are plotted as a guide for eyes

First, EAC densities increase as a function of $\xi_{W A X S}$ for both samples until $t_{98}$ is reached and then they decrease slightly beyond this time. Additionally, evolution of EAC density is always 1.6 times higher for NR2.5 than the one for NR1.5. This suggests that the kinetics of all the involved chemical reactions are proportional to the initial amount of sulfur (and CBS). The decrease of EAC with $\mathrm{t}$ above $t_{98}$ cannot be ascribed to thermolytic chain scission, as it was shown in literature that chain scission mechanisms are negligible during thermal ageing of pure isoprene, even at $170^{\circ} \mathrm{C}$ (within the reasonable assumption that the presence of bridges and vulcanisation system has no influence on this) [10], [39]. Besides, ZnS concentration still increases, which indicates that formation of crosslink precursors still occurs, and therefore that sulphur bridges are likely to be formed. Nevertheless, these additional sulphur bridges, and those possibly formed via the transformation of long bridges in two shorter bridges [18] does not hinder the decrease of the EAC density. An explanation of this result is given by the literature which suggests that a significant part of the polysulfidic bridges can be transformed as non-elastic cyclic sulphides groups along the polymer chains.

Conversely to what is observed at $150^{\circ} \mathrm{C}$, the EAC crosslink densities of the optimally cured samples increase during TO or TH ageing at $77^{\circ} \mathrm{C}$. Thus, more numerous active bridges are created than destroyed (destruction via 
the formation of polysulfidic cycles). As shown by the initial value of $\xi_{\mathrm{WAxs}}$ (cf. Fig. 10) for both materials, the $\mathrm{ZnS}$ concentration does not evolve. Thus, as said previously, other mechanisms than the ones involved during the vulcanization process at high temperature are responsible for the formation of new crosslinks. To confirm this, the evolution of EAC density and $\xi_{\text {WAXs }}$ has been measured during the $\mathrm{TH}$ ageing at $77^{\circ} \mathrm{C}$ of a non-cured NR2.5 (cf. Fig. 13). The EAC density increases up to $5.10^{-4}$ mol.cm ${ }^{-3}$ while $\xi_{\text {WAXs }}$ stays nul, showing that crosslinking can occur at $77^{\circ} \mathrm{C}$ without the involvement of the active sulfurating agent appearing in the vulcanization process at high temperature (cf. Fig. 3). The stabilization of the EAC after 7 days may be explained by the total consumption of the free sulfur. Some supplementary experiments measuring the residual sulfur concentration during ageing would be necessary to confirm this assumption. This total consumption of residual sulphur could also explain the absence of supplementary crosslinking during the $\mathrm{TH}$ ageing of NR2.5_Eff (cf. Fig. 6).

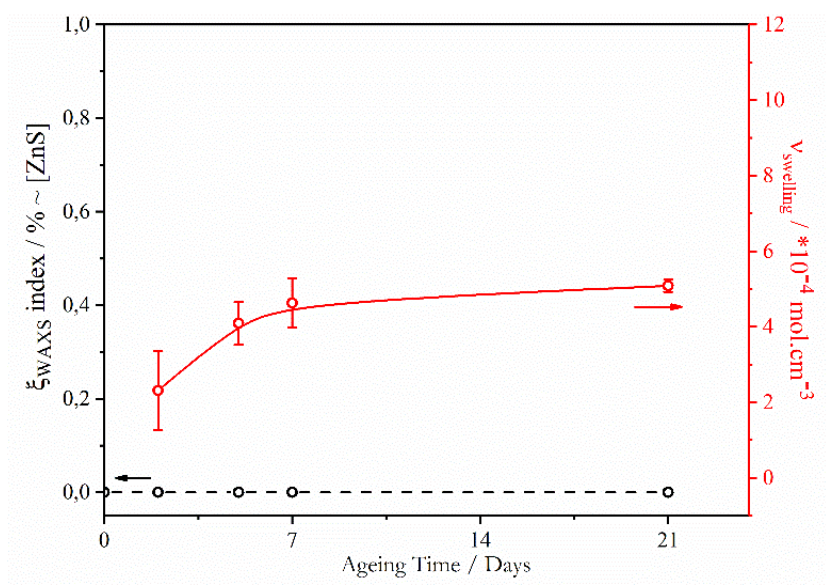

Fig. 13 : Evolution of $\xi_{W A X S}$ (black) and active chain density (red) during thermal ageing of a non-cured NR2.5 from 0 to 21 days

The crosslinks formed after 7 days in NR2.5 are weak bridges (cf. Fig. 11). They may be formed by the process often named "unaccelerated sulfur vulcanization" in which only the consumption of sulfur $\left(\mathrm{S}_{8}\right)$ is involved. As reviewed by Krejsa [29], $S_{8}$ is able to undergo homolytic (radical) or heterolytic (polar/ionic) ring opening reactions to form long polysulfidic bridges (as observed by NMR studies [41]). There is no difference between $\mathrm{TH}$ and TO ageing at $77^{\circ} \mathrm{C}$ during the first 7 days as the consumption of residual antioxidants inhibits the role of the oxygen. For conventionally crosslinked rubber NR2.5 and NR1.5, and for longer ageing duration, TO ageing leads to supplementary crosslinks (cf. Fig. $6 \&$ 7). It is known that ageing by oxygen at high temperature 
$\left(140^{\circ} \mathrm{C}\right)$ can lead to crosslinks made of peroxide bridge [10]; nevertheless, the $\mathrm{M}_{\mathrm{n}}$ decreases of pure polyisoprene during $\mathrm{TO}$ ageing at $77^{\circ} \mathrm{C}$ (cf. Fig. 9a) suggests that such mechanism is negligible at this temperature. Thus, the formation of crosslinks needs here reaction(s) involving both oxygen and sulfur. This might be a reaction between oxygen and cyclic and pendant sulfides groups which are numerous in conventionally crosslinked NR [42], and are randomly distributed along the polymer chain. Additionally, the non-evolution of EAC density and $\delta_{p}$ for NR2.5_Eff (cf. Fig. 6 and 7) in the presence of oxygen from 7 to 21 days can be explained by the low concentration of reactive polysulfidic groups along the backbone (related to the lower initial sulphur concentration) [43].

The formation of supplementary crosslinks during ageing raises the question of their spatial distribution. From thermoporosimetry experiments, Fig. 14 presents the comparative distribution of the solvent melting temperature for the aged and non-aged NR1.5 and NR2.5. Heterogeneities in the spatial distribution of the crosslinks already exist in the samples prior thermo-oxidative ageing, particularly for non-aged NR2.5, for which the shape of the peak suggests the presence of domains with a high EAC density. TO ageing leads to a shift of the distribution towards low temperature and the magnitude of this transformation is more important for NR2.5. This is consistent with EAC density evolution. In addition, ageing leads to appearance of a second peak at low temperature indicating that the crosslinking is spatially heterogeneous. This phenomenon is more pronounced in the case of NR2.5, in other words, aged NR2.5 is expected to have a network more heterogeneous than NR1.5. It is worth mentioning that the same comment can be made from the observation of the solvent crystallization curves (cf. Fig. S4).
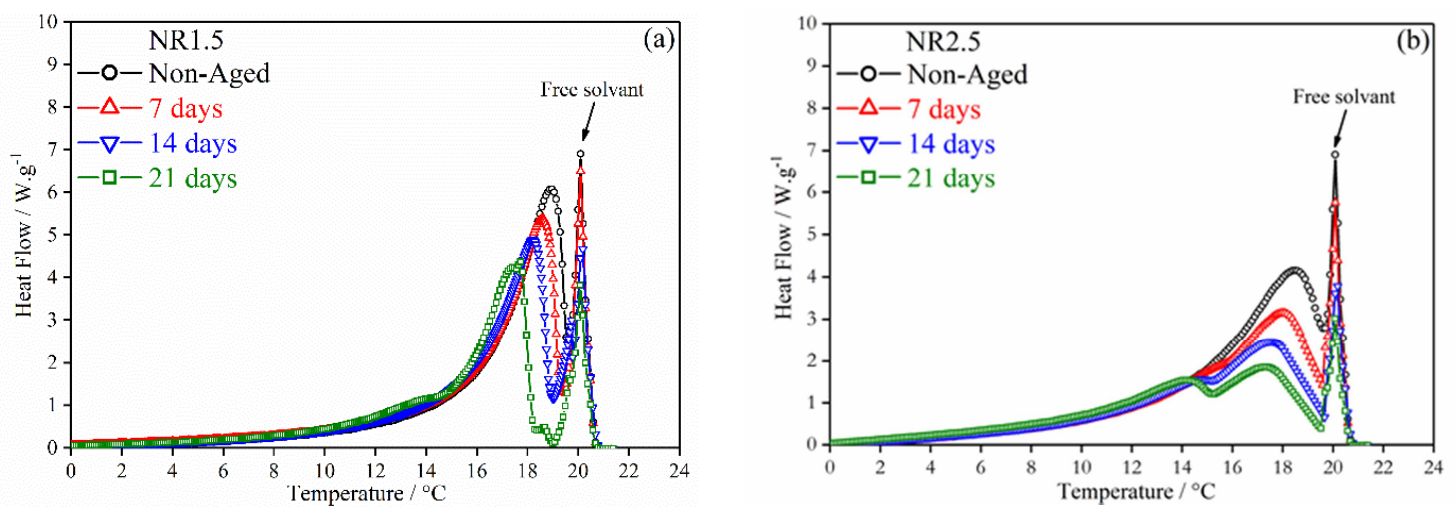
Fig. 14 : Heating curves from thermoporosimetry experiments for (a) NR1.5 and (b) NR2.5 aged from 0 to 21 days during $\mathrm{TO}$ at $77^{\circ} \mathrm{C}$

To sum up, a schematic vision of the network evolution in conventionally crosslinked natural rubber during TO ageing is given in Fig. 15. First, it is often claimed that weakly and densely crosslinked phases are formed after the vulcanization process [44]-[46]. The latter consist of $\mathrm{ZnO} / \mathrm{ZnS}$ clusters surrounded by a high crosslinked phase. Such vision is partly confirmed by the thermoporosimetry curves of unaged NR1.5 and NR2.5 (cf. Fig. 14, and Fig. S5 in SI) which show a small shoulder at around $16^{\circ} \mathrm{C}$ and $15^{\circ} \mathrm{C}$ respectively. Besides, cyclic sulfide pendant groups are formed along the polymer chain when NR is conventionally crosslinked [43]. Some crosslinks precursors (as $\xi_{\text {WAXS }} \neq 1$ ) and residual antioxidants also remain in the network after the vulcanization process (cf. Fig. 15a). During the first 7 days of TO ageing, whereas vulcanization reactions are not activated and $\xi_{\text {WAXS }}$ stays constant, residuals antioxidants and free sulfur are consumed, leading mainly to the formation of long polysulfidic bridges (cf. Fig. 15b). Once antioxidants are consumed, oxygen leads to the formation, via reaction(s) involving the oxygen, of new crosslinks, likely from polysulfidic cycle pendant groups (cf. Fig. 15c). Such mechanisms are also spatially heterogeneous, and decrease the fraction of rubber which can be highly swollen, in other words they suppress the weakly crosslinked domains and may create domains too crosslinked to swell. To be complete, in spite of the large predominance of crosslinking mechanisms, TO leads also to relatively few chain scissions, and to the formation of pendants groups along the polymer chain. The schemes in Fig. 15 summarize these interpretations. 


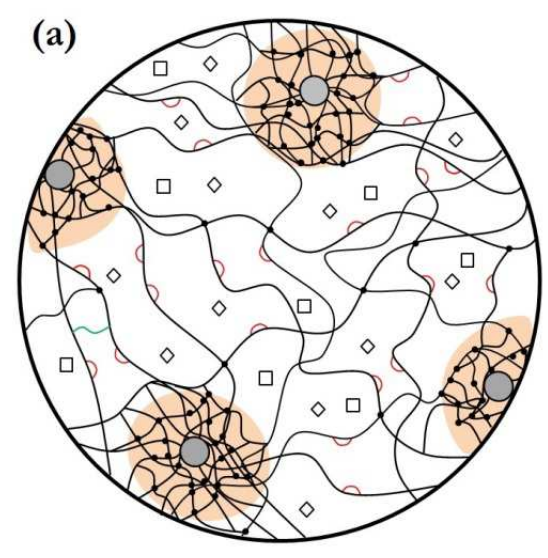

(b)

Legend:
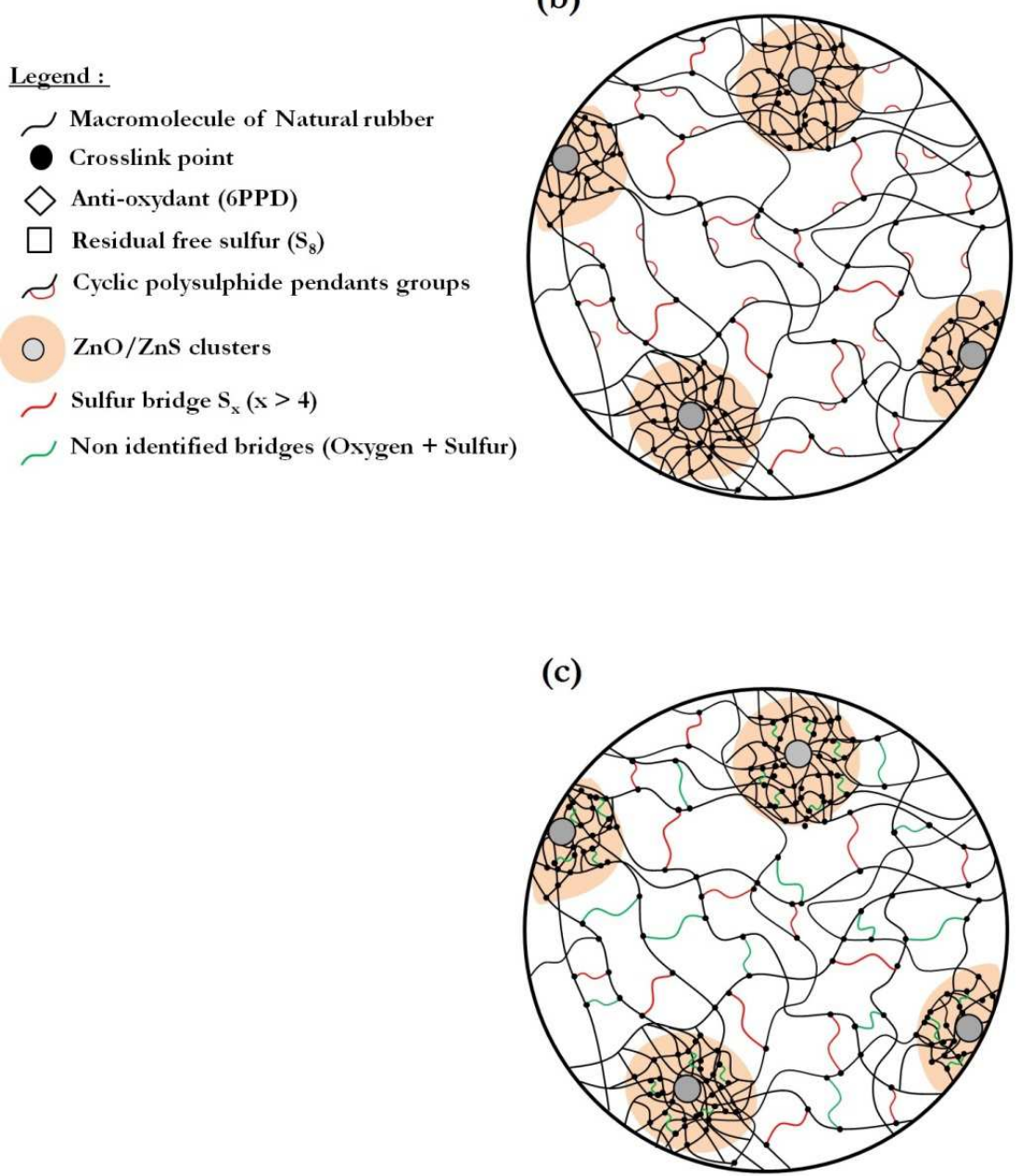

Fig. 15 : Proposed schemes to highlight to network structure (a) after the vulcanization process and its evolution during TO ageing at $77^{\circ} \mathrm{C}$ (b) after 7 days and (c) 14 days. 


\section{CONCLUSIONS}

This work aims at understanding the chemicals mechanisms involved during thermo-oxidative ageing at $77^{\circ} \mathrm{C}$ on a conventionally crosslinked natural rubber. The main findings are the following:

- It is important to keep in mind that in conventionally crosslinked system, the vulcanization process is far to be finished at $t_{98}$. An important consequence is that kinetics models cannot be built only from the mechanical properties evolution during the vulcanization process when it stopped at that time.

- TO ageing is similar to TH ageing as far as the concentration of antioxidants remaining form the vulcanization process, is large enough.

- $\quad \mathrm{TH}$ ageing at $77^{\circ} \mathrm{C}$ involves chemical mechanisms which are different from the ones met during the material processing.

- At $77^{\circ} \mathrm{C}$, TH ageing leads to the formation of weak long polysulfidic bridges from the residual free sulfur remaining in the unaged material. This process last as long as all the free sulfur is consumed.

- Shortening of the polysulfidic bridges does not seem to be a predominant mechanism during $\mathrm{TH}$ at $77^{\circ} \mathrm{C}$.

- During TO at $77^{\circ} \mathrm{C}$, chemical reactions involving the oxygen take place to lead to supplementary crosslinking in conventionally crosslinked materials, which suggests that these reactions need the presence of cyclic sulfide pendant groups (crosslinking being negligible, compared to chain scission mechanisms, in materials in which these groups cannot be present). However, some question remains on the chemical nature of the bridges created during TO ageing. A specific study devoted to this question would be undoubtedly interesting...even though it is likely very difficult, given the complexity of NR and the vulcanization recipe, to be able to associate among all the chemical species formed during TO, those specifically forming these supplementary crosslinks.

- In spite of the large predominance of crosslinking mechanisms, TO leads also to relatively few chain scissions, and to the formation of pendants groups along the polymer chain.

- The supplementary crosslinks induced by ageing seem to enhance the heterogeneity of the spatial distribution of the crosslinks - already existing in the initial material - and to create highly crosslinked domains.

To conclude this work clearly proves that the use, for conventional NR, of accelerated ageing procedure (at temperature for instance above $100^{\circ} \mathrm{C}$ ), to address the question of its durability, is highly questionable. 


\section{SUPPORTING INFORMATIONS (SI)}

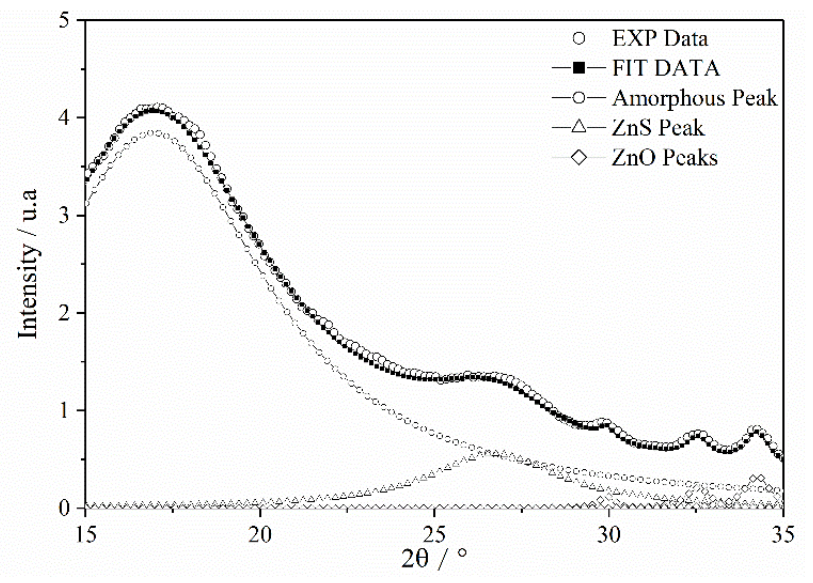

Fig. S1 : Deconvolution and fitting of a WAXS pattern.

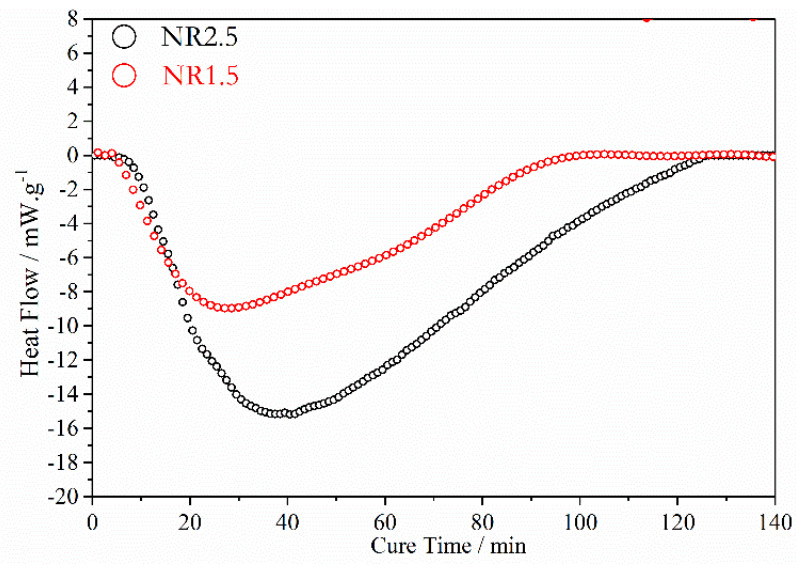

Fig. S2 : Exothermic peak during the vulcanization process at $150^{\circ} \mathrm{C}$. 


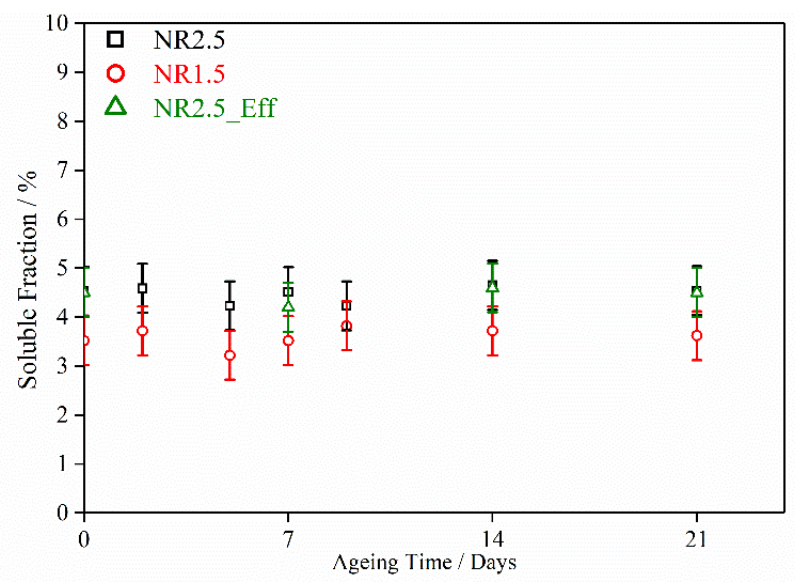

Fig. S3 : Evolution of the soluble fraction Fs during thermo-oxidative ageing at $77^{\circ} \mathrm{C}$.
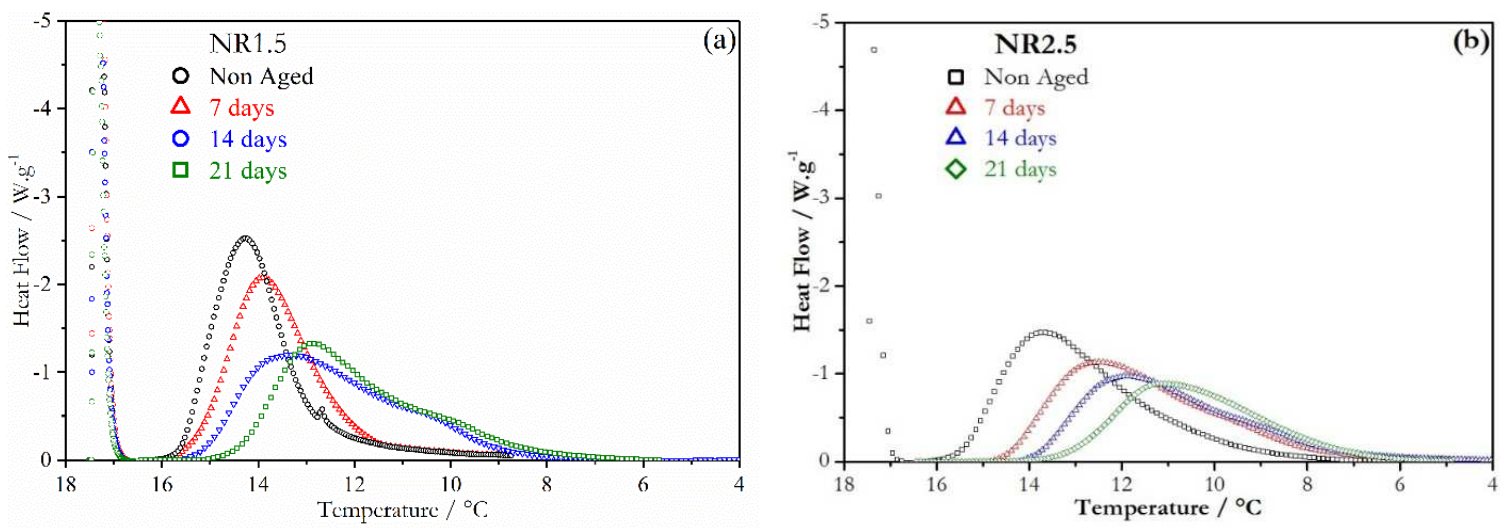

Fig. S4 : Cooling curves from thermoporosimetry experiments for (a) NR1.5 and (b) NR2.5 aged from 0 to 21 days swelling in hexadecane 

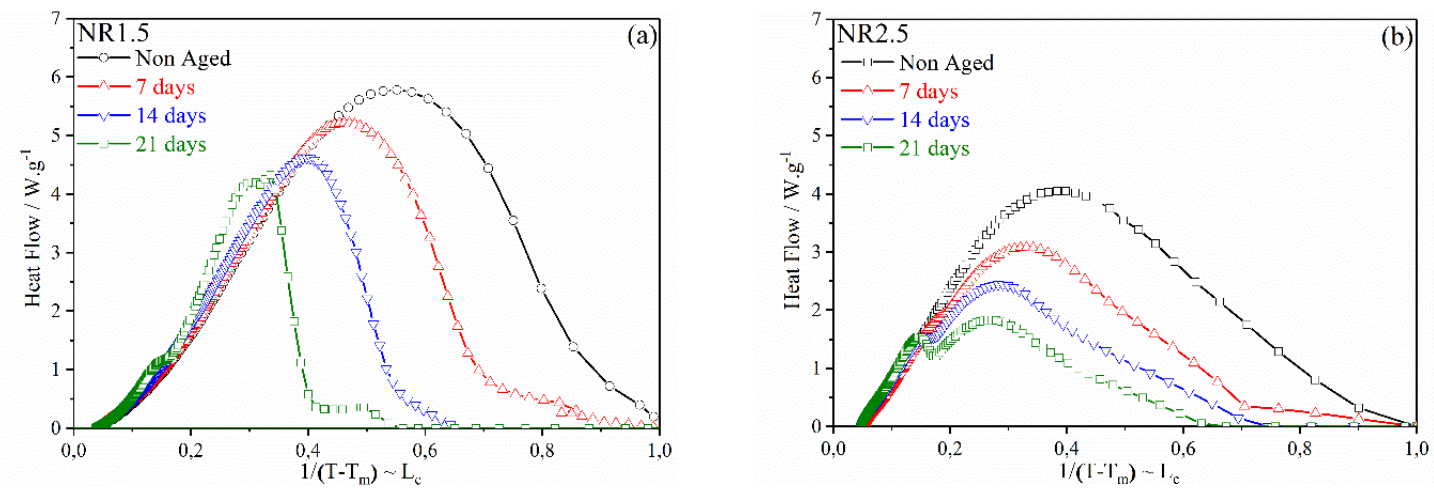

Fig. S5 : Heat flow normalized by the dried sample weight as a function of $1 /\left(\mathrm{T}_{\mathrm{m}}^{\circ}-\mathrm{T}_{\mathrm{m}}\right)$ described by the Gibbs-Thomson equation

According to the Gibbs-Thomson equation (Eq. S1), a "pore" size in the polymer network can be calculated from the melting temperature of the solvent it contains :

$\mathrm{T}_{\mathrm{m}}^{0}-\mathrm{T}_{\mathrm{m}}=\frac{2 \sigma_{\mathrm{SL}} \mathrm{T}_{\mathrm{m}}^{0}}{\mathrm{~L}_{\mathrm{c}} \Delta \mathrm{H}_{\mathrm{f}}}$

Where, $\Delta \mathrm{H}_{\mathrm{f}}$ is the solvent melting enthalpy, $\mathrm{L}$ the crystal radius within the assumption of a spherical pore, $\sigma_{\mathrm{SL}}$ is the solid-liquid interfacial energy and $\mathrm{T}_{\mathrm{m}}^{0}$ the free solvent melting temperature which is around $21^{\circ} \mathrm{C}$ for hexadecane. $\sigma_{\mathrm{SL}}$ is not known for the hexadecane-NR couple. However, the crystal radius can be considered proportional to $1 /\left(\mathrm{T}_{\mathrm{m}}^{0}-\mathrm{T}_{\mathrm{m}}\right)$. Normalized heat flow is plotted as a function of $1 /\left(\mathrm{T}_{\mathrm{m}}^{0}-\mathrm{T}_{\mathrm{m}}\right)$ for NR1.5 and NR2.5 in Fig. S5. For both samples, the formation of large crystals is less pronounced after TO ageing. As the consequence, crosslinking mechanisms decrease the fraction of rubber which can be highly swollen (i.e. corresponding the formation of larger crystals when solvent crystallize). In other words they suppress the weakly crosslinked domains and may create domains too crosslinked to swell. 
Supplementary information S6 : Calculation of $\delta_{\mathrm{p}}$ by the use of two good solvents

We assumed equality between $v_{\text {sweeling }}$ measured by the used of cyclohexane $v_{\text {sweeling }}$ measured by the used of toluene:

$\mathrm{v}_{\text {swelling }}($ Toluene $)=\mathrm{v}_{\text {swelling }}($ Cyclohexane $)$

Considering the Flory-Rehner approach [24] :

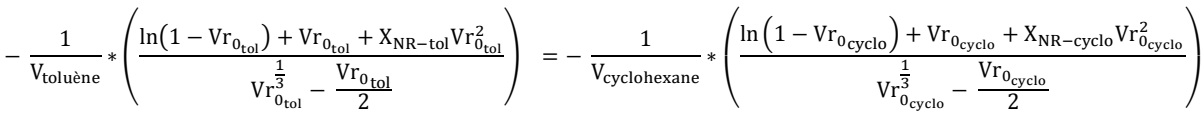

$$
\begin{aligned}
& \frac{\mathrm{V}_{\text {cyclo }}}{\mathrm{V}_{\text {toluène }}} *\left(\frac{\ln \left(1-\mathrm{Vr}_{0_{\text {tol }}}\right)+\mathrm{Vr}_{0_{\text {tol }}}+\mathrm{X}_{\mathrm{NR}-\text { tol }} \mathrm{Vr}_{0_{\text {tol }}^{2}}^{2}}{\mathrm{Vr}_{0_{\text {tol }}}^{\frac{1}{3}}-\frac{\mathrm{Vr}_{0_{\text {tol }}}}{2}}\right) *\left(\mathrm{Vr}_{0_{\text {cyclo }}}^{\frac{1}{3}}-\frac{\mathrm{Vr}_{0_{\text {cyclo }}}}{2}\right)=\ln \left(1-\mathrm{Vr}_{0_{\text {cyclo }}}\right)+\mathrm{Vr}_{0_{\text {cyclo }}}+\mathrm{X}_{\mathrm{NR}-\text { cyclo }} \mathrm{Vr}_{0_{\text {cyclo }}}{ }^{2} \\
& \mathrm{X}_{\mathrm{NR}-\text { cyclo }}=\frac{\mathrm{V}_{\text {cyclo }}}{\mathrm{V}_{\text {toluène }} * \mathrm{Vr}_{0_{\text {cyclo }}}{ }^{2}} *\left(\frac{\ln \left(1-\mathrm{Vr}_{0_{\text {tol }}}\right)+\mathrm{Vr}_{0_{\text {tol }}}+\mathrm{X}_{\mathrm{NR} \text {-tol }} \mathrm{Vr}_{\mathrm{t}_{\text {tol }}}^{2}}{\mathrm{Vr}_{0_{\text {tol }}}^{\frac{1}{3}}-\frac{\mathrm{Vr}_{\mathrm{t}_{\text {tol }}}}{2}}\right) *\left(\mathrm{Vr}_{0_{\text {cyclo }}}^{\frac{1}{3}}-\frac{\mathrm{Vr}_{0_{\text {cyclo }}}}{2}\right)-\frac{\ln \left(1-\mathrm{Vr}_{0_{\text {cyclo }}}\right)}{\mathrm{Vr}_{0_{\text {cyclo }}}^{2}}-\frac{1}{\mathrm{Vr}_{0_{\text {cyclo }}}} \\
& \mathrm{X}_{\mathrm{NR} \text {-cyclo }}=\frac{\mathrm{V}_{\text {cyclo }} *\left(\mathrm{Vr}_{\mathrm{c}_{\text {cyclo }}}^{\frac{1}{3}}-\frac{\mathrm{Vr}_{0_{\text {cyclo }}}}{2}\right)}{\mathrm{V}_{\text {toluène }} * \mathrm{Vr}_{0_{\text {cyclo }}}^{2} *\left(\mathrm{Vr}_{0_{\text {tol }}}^{\frac{1}{3}}-\frac{\mathrm{Vr}_{0_{\text {tol }}}}{2}\right)} *\left(\ln \left(1-\mathrm{Vr}_{0_{\text {tol }}}\right)+\mathrm{Vr}_{0_{\text {tol }}}+\mathrm{X}_{\mathrm{NR}-\text { tol }} \mathrm{Vr}_{0_{\text {tol }}}^{2}\right)-\frac{\ln \left(1-\mathrm{Vr}_{0_{\text {cyclo }}}\right)}{\mathrm{Vr}_{0_{\text {cyclo }}{ }^{2}}}-\frac{1}{\mathrm{Vr}_{0_{\text {cyclo }}}}
\end{aligned}
$$

With some constants defined by :

$$
\begin{aligned}
& A=\frac{\mathrm{V}_{\text {cyclo }} *\left(\mathrm{Vr}_{0_{\text {cyclo }}}^{\frac{1}{3}}-\frac{\mathrm{Vr}_{0_{\text {cyclo }}}}{2}\right)}{\mathrm{V}_{\text {toluène }} * \mathrm{Vr}_{0_{\text {cyclo }}}^{2} *\left(\mathrm{Vr}_{0_{\text {tol }}}^{\frac{1}{3}}-\frac{\mathrm{Vr}_{0_{\text {tol }}}}{2}\right)} \\
& \mathrm{C}_{1}=\mathrm{A} * \ln \left(1-\mathrm{Vr}_{0_{\text {tol }}}\right) \\
& \mathrm{C}_{2}=\mathrm{A} * \mathrm{Vr}_{0_{\text {tol }}} \\
& \mathrm{C}_{3}=\mathrm{A} * \mathrm{Vr}_{0_{\text {tol }}}^{2} \\
& \mathrm{C}_{4}=-\frac{\ln \left(1-\mathrm{Vr}_{0_{\text {cyclo }}}\right)}{\mathrm{Vr}_{0_{\text {cyclo }}}^{2}}-\frac{1}{\mathrm{Vr}_{0_{\text {cyclo }}}}
\end{aligned}
$$


We have:

$\mathrm{C}_{1}+\mathrm{C}_{2}+\mathrm{C}_{4}+\mathrm{C}_{3} * \mathrm{X}_{\mathrm{NR}-\text { tol }}=\mathrm{X}_{\mathrm{NR}-\text { cyclo }}$

Considering the widely used equation to estimate the interaction parameter:

$\chi_{\mathrm{NR}-\mathrm{tol}}=0.34+\frac{\mathrm{V}_{\mathrm{tol}}}{\mathrm{RT}} *\left(\delta_{\mathrm{p}}-\delta_{\mathrm{tol}}\right)^{2}$

$\chi_{\mathrm{NR}-\text { cyclo }}=0.34+\frac{\mathrm{V}_{\text {cyclo }}}{\mathrm{RT}} *\left(\delta_{\mathrm{p}}-\delta_{\text {cyclo }}\right)^{2}$

With (S5.11) and (S5.12), we have :

$\mathrm{C}_{1}+\mathrm{C}_{2}+\mathrm{C}_{4}+\mathrm{C}_{3} *\left\{0.34+\frac{\mathrm{V}_{\text {tol }}}{\mathrm{RT}}\left(\delta_{\mathrm{p}}{ }^{2}-2 \delta_{\mathrm{p}} \delta_{\text {tol }}+\delta_{\text {tol }}{ }^{2}\right)\right\}=0.34+\frac{\mathrm{V}_{\text {cyclo }}}{\mathrm{RT}} *\left(\delta_{\mathrm{p}}^{2}-2 \delta_{\mathrm{p}} \delta_{\text {cyclo }}+\delta_{\text {cyclo }}{ }^{2}\right)$

So,

$\begin{aligned} & \mathrm{C}_{1}+\mathrm{C}_{2}+\mathrm{C}_{4}+0.34 *\left(\mathrm{C}_{3}-1\right)+\frac{\delta_{\mathrm{p}}^{2}}{\mathrm{RT}} *\left\{\mathrm{C}_{3} \mathrm{~V}_{\mathrm{tol}}-\mathrm{V}_{\text {cyclo }}\right\}+\frac{\delta_{\mathrm{p}}}{\mathrm{RT}} *\left\{-2 \mathrm{C}_{3} \mathrm{~V}_{\mathrm{tol}} \delta_{\text {tol }}+2 \mathrm{~V}_{\text {cyclo } *} \delta_{\text {cyclo }}\right\} \\ &+\frac{1}{\mathrm{RT}}\left\{\mathrm{C}_{3} \mathrm{~V}_{\text {tol }} \delta_{\text {tol }}{ }^{2}-\mathrm{V}_{\text {cyclo }} \delta_{\text {cyclo }}{ }^{2}\right\}=0\end{aligned}$

Finally, (S6.14) is in the form of a second-degree equation:

$\mathrm{a} \delta_{\mathrm{p}}^{2}+\mathrm{b} \delta_{\mathrm{p}}+\mathrm{c}=0$

With :

$\mathrm{a}=\frac{\mathrm{C}_{3} \mathrm{~V}_{\text {tol }}-\mathrm{V}_{\text {cyclo }}}{\mathrm{RT}}$
$\mathrm{b}=\frac{2\left(\mathrm{~V}_{\text {cyclo } *} \delta_{\text {cyclo }}-\mathrm{C}_{3} \mathrm{~V}_{\text {tol }} \delta_{\text {tol }}\right)}{\mathrm{RT}}$
$\mathrm{c}=\mathrm{C}_{1}+\mathrm{C}_{2}+\mathrm{C}_{4}+0.34 *\left(\mathrm{C}_{3}-1\right)+\frac{\left(\mathrm{C}_{3} \mathrm{~V}_{\text {tol }} \delta_{\text {tol }}{ }^{2}-\mathrm{V}_{\text {cyclo }} \delta_{\text {cyclo }}{ }^{2}\right)}{\mathrm{RT}}$ 


\section{REFERENCES}

[1] L. C. Yanyo, "Effect of crosslinking type on the fracture of natural rubber," Int. J. Fract., vol. 39, pp. $103-110,1989$.

[2] C. M. Kok and V. H. Yee, "The effects of crosslink density and crosslink type on the tensile and tear strengths of NR, SBR and EPDM gum vulcanizates,” Eur. Polym. J., vol. 22, no. 4, pp. 341-345, 1986.

[3] A. W. Birkley, "Rubbery materials and their compounds JA Brydson, Elsevier Applied Science, London,

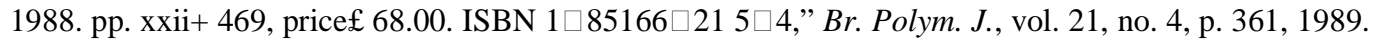

[4] S. G. Kim and S. H. Lee, "Effect of Crosslink Structures on the Fatigue Crack Growth Behavior of NR Vulcanizates with Various Aging Conditions," Rubber Chemistry and Technology, vol. 67, no. 4. pp. 649-661, 1994.

[5] R. L. Fan, Y. Zhang, F. Li, Y. X. Zhang, K. Sun, and Y. Z. Fan, "Effect of high-temperature curing on the crosslink structures and dynamic mechanical properties of gum and N330-filled natural rubber vulcanizates," Polym. Test., vol. 20, no. 8, pp. 925-936, 2001.

[6] N. J. Morrison and M. Porter, "Temperature Effects on the Stability of Intermediates and Crosslinks in Sulfur Vulcanization,” Rubber Chemistry and Technology, vol. 57, no. 1. pp. 63-85, 1984.

[7] J. T. South, S. W. Case, and K. L. Reifsnider, "Effects of Thermal Aging on The Mechanical Properties of Natural Rubber," Rubber Chem. Technol., vol. 76, no. 4, pp. 785-802, 2003.

[8] C. Sung-Seen, "Influence of Thermal Aging on change of crosslink Density and deformation of Natural Rubber Vulcanizates,” Bull. Korean Chem. Soc., vol. 21, 2000.

[9] C. J. Ohlemacher and G. R. Hamed, "Aging with Applied Strain of A Black-Filled Natural Rubber Vulcanizate. Part I: Network Changes,” Rubber Chem. Technol., vol. 81, no. 4, pp. 650-670, 2008.

[10] X. Colin, L. Audouin, and J. Verdu, "Kinetic modelling of the thermal oxidation of polyisoprene elastomers. Part 3: Oxidation induced changes of elastic properties," Polym. Degrad. Stab., vol. 92, no. 5, pp. 906-914, 2007.

[11] X. Colin, L. Audouin, and J. Verdu, "Kinetic modelling of the thermal oxidation of polyisoprene elastomers. Part 1: Unvulcanized unstabilized polyisoprene,” Polym. Degrad. Stab., vol. 92, no. 5, pp. 886-897, 2007.

[12] A. Ahagon, M. Kida, and H. Kaidou, "Aging of Tire Parts during Service. I. Types of Aging in Heavy- 
Duty Tires,” Rubber Chemistry and Technology, vol. 63, no. 5. pp. 683-697, 1990.

[13] E. F. Ngolemasango, M. Bennett, and J. Clarke, "Kinetics of the effect of ageing on tensile properties of a natural rubber compound,” J. Appl. Polym. Sci., vol. 102, no. 4, pp. 3732-3740, 2006.

[14] H. Kaidou and A. Ahagon, "Aging of Tire Parts during Service. II. Aging of Belt-Skim Rubbers in Passenger Tires," Rubber Chemistry and Technology, vol. 63, no. 5. Rubber Chemical \& Technology, pp. 698-712, 1990.

[15] J. M. Baldwin and D. R. Bauer, "Rubber Oxidation and Tire Aging - A Review," Rubber Chem. Technol., vol. 81, no. 2, pp. 338-358, 2008.

[16] J. M. Baldwin, D. R. Bauer, and K. R. Ellwood, "Rubber aging in tires. Part 1: Field results," Polym. Degrad. Stab., vol. 92, no. 1, pp. 103-109, 2007.

[17] D. R. Bauer, J. M. Baldwin, and K. R. Ellwood, "Rubber aging in tires. Part 2: Accelerated oven aging tests," Polym. Degrad. Stab., vol. 92, no. 1, pp. 110-117, 2007.

[18] N. M. Mathew and S. K. De, "Thermo-oxidative ageing and its effect on the network structure and fracture mode of natural rubber vulcanizates,” Polymer (Guildf)., vol. 24, no. 8, pp. 1042-1054, 1983.

[19] G. R. Hamed and J. Zhao, "Tensile Behavior after Oxidative Aging of Gum and Black-Filled Vulcanizates of SBR and NR,” Rubber Chem. Technol., vol. 72, no. 4, pp. 721-730, 1999.

[20] J. M. Baldwin, D. R. Bauer, and K. R. Ellwood, “Accelerated Aging of Tires, Part III," Rubber Chem. Technol., vol. 78, no. 5, pp. 767-776, 2005.

[21] S.-S. Choi, "Change of Crosslink Density of Sufur-Cured NR Vulcanizates by Thermal Ageing," Korea Polymer Journal, vol. 7, no. 2. pp. 108-115, 1999.

[22] J. R. Shelton, “Aging and Oxidation of Elastomers," Rubber Chemistry and Technology, vol. 30, no. 5. pp. 1251-1290, 1957.

[23] J. R. Shelton and W. T. Wickham, "Carbon Black in the Oxidation of Butadiene-Styrene Vulcanizates," Ind. Eng. Chem., vol. 49, no. 8, pp. 1277-1282, 1957.

[24] P. J. Flory and J. Rehner, "Statistical Mechanics of Cross-Linked Polymer Networks I. Rubberlike Elasticity," J. Chem. Phys., vol. 11, no. 11, p. 512, 1943.

[25] J. L. Valentín, J. Carretero-González, I. Mora-Barrantes, W. Chassé, and K. Saalwächter, "Uncertainties in the determination of cross-link density by equilibrium swelling experiments in natural rubber," Macromolecules, vol. 41, no. 13, pp. 4717-4729, 2008.

[26] R. F. Blanks and J. M. Prausnitz, "Thermodynamics of Polymer Solubility in Polar and Nonpolar 
Systems," Ind. Eng. Chem. Fundam., vol. 3, no. 1, pp. 1-8, 1964.

[27] G. McKenna, "Melting of Solvents Nanoconfined by Polymers and Networks," J. Polym. Sci. Part B Polym. Phys., vol. 45, no. April, pp. 1390-1398, 2007.

[28] S. Etienne, J. Y. Cavaille, J. Perez, R. Point, and M. Salvia, "Automatic system for analysis of micromechanical properties," Rev. Sci. Instrum., vol. 53, no. 8, pp. 1261-1266, 1982.

[29] M. R. Krejsa and J. L. Koenig, “A Review of Sulfur Crosslinking Fundamentals for Accelerated and Unaccelerated Vulcanization," Rubber Chem. Technol., vol. 66, no. 3, pp. 376-410, 1993.

[30] V. Chapman, A and M. Porter, "Suphur vulcanization chemistry," in Natural Rubber Science And Technology, Oxford Uni., A. D. Roberts, Ed. 1989, pp. 511-620.

[31] Y. Ikeda et al., "Dinuclear Bridging Bidentate Zinc / Stearate Complex in Sulfur Cross- Linking of Rubber," 2014.

[32] M. F. Bukhina, Y. L. Morozov, P. M. Van de Ven, and J. W. M. Noordermeer, "Mould fouling of EPDM rubber compounds," KGK-Kautschuk und Gummi Kunststoffe, vol. 56, no. 4, pp. 172-183, 2003.

[33] R. M. Ali, N. I. Harun, A. M. M. Ali, and M. Z. A. Yahya, "Effect of ZnS Dispersoid in Structural and Electrical Properties of Plasticized CA-NH 4 I,” Phys. Procedia, vol. 25, pp. 293-298, 2012.

[34] D. W. Brazier and G. H. Nickel, “Thermoanalytical Methods in Vulcanizate Analysis I. Differential Scanning Calorimetry and the Heat of Vulcanization," Rubber Chemistry and Technology, vol. 48, no. 1. p. 26, 1975.

[35] D. W. Brazier, G. H. Nickel, and Z. Szentgyorgyi, "Enthalpic Analysis of Vulcanization by Calorimetry. Thiuram Monosulfide/Sulfur Vulcanization of NR, BR and SBR,” Rubber Chemistry and Technology, vol. 53, no. 1. Rubber Chemical \& Technology, pp. 160-175, 1980.

[36] I. Kende, T. L. Pickering, and A. V. Tobolsky, "The Dissociation Energy of the Tetrasulfide Linkage,” J. Am. Chem. Soc., vol. 87, no. 24, pp. 5582-5586, 1965.

[37] S. S. Choi, D. H. Han, S. W. Ko, and H. S. Lee, "Thermal aging behaviors of elemental sulfur-free polyisoprene vulcanizates," Bull. Korean Chem. Soc., vol. 26, no. 11, pp. 1853-1855, 2005.

[38] P. R. Dluzneski, "Peroxide Vulcanization of Elastomers,” Rubber Chem. Technol., vol. 74, pp. 451-492, 2001.

[39] G. J. van Amerongen, "Oxidative and Nonoxidative Thermal Degradation of Rubber," Rubber Chem. Technol., vol. 29, no. 3, pp. 857-879, 1956.

[40] X. Colin, L. Audouin, J. Verdu, and M. Le Huy, "Kinetic modelling of the thermal oxidation of 
polyisoprene elastomers. Part 2: Effect of sulfur vulcanization on mass changes and thickness distribution of oxidation products during thermal oxidation,” Polym. Degrad. Stab., vol. 92, no. 5, pp. 898-905, 2007.

[41] M. Mori and J. L. Koenig, A Review of High-Resolution NMR Studies of Vulcanized Elastomers, vol. 34, no. C. 1997.

[42] C. R. Parks and O. Lorenz, "The effect of network structure on aging of natural rubber vulcanizates," I\&EC Prod. Res. Dev., vol. 2, no. 4, pp. 279-283, 1963.

[43] M. Akiba, "Vulcanization and crosslinking in elastomers," Prog. Polym. Sci., vol. 22, no. 3, pp. 475$521,1997$.

[44] H. Dohi and S. Horiuchi, "Heterogeneity of a vulcanized rubber by the formation of ZnS clusters," Polymer (Guildf)., vol. 48, no. 9, pp. 2526-2530, 2007.

[45] Y. Ikeda et al., "Vulcanization: New focus on a traditional technology by small-angle neutron scattering," Macromolecules, vol. 42, no. 7, pp. 2741-2748, 2009.

[46] T. Suzuki et al., "Nonuniformity in cross-linked natural rubber as revealed by contrast-variation smallangle neutron scattering," Macromolecules, vol. 43, no. 3, pp. 1556-1563, 2010. 